\title{
Fluxes and concentrations of volatile organic compounds above central London, UK
}

\author{
B. Langford ${ }^{1,2}$, E. Nemitz ${ }^{2}$, E. House ${ }^{2,3}$, G. J. Phillips ${ }^{2}$, D. Famulari ${ }^{2}$, B. Davison ${ }^{1}$, J. R. Hopkins ${ }^{4}$, A. C. Lewis ${ }^{4}$, and \\ C. N. Hewitt ${ }^{1}$ \\ ${ }^{1}$ Lancaster Environment Centre, Lancaster University, LA1 4YQ, Lancaster, UK \\ ${ }^{2}$ Biogeochemistry Programme, Centre for Ecology and Hydrology (Edinburgh), Bush Estate, EH26 0QB, Penicuik, UK \\ ${ }^{3}$ School of Chemistry, Edinburgh University, West Mains Road, EH9 3JJ, Edinburgh, UK \\ ${ }^{4}$ National Centre for Atmospheric Science, University of York, YO10 5DD, York, UK
}

Received: 3 July 2009 - Published in Atmos. Chem. Phys. Discuss.: 14 August 2009

Revised: 11 December 2009 - Accepted: 8 January 2010 - Published: 22 January 2010

\begin{abstract}
Concentrations and fluxes of eight volatile organic compounds (VOCs) were measured during October 2006 from a high telecom tower above central London, as part of the CityFlux contribution to the REPARTEE I campaign. A continuous flow disjunct eddy covariance technique with analysis by proton transfer reaction mass spectrometry was used. Daily averaged VOC mixing ratios were within the range $1-19 \mathrm{ppb}$ for the oxygenated compounds (methanol, acetaldehyde and acetone) and $0.2-1.3 \mathrm{ppb}$ for the aromatics (benzene, toluene and $\mathrm{C}_{2}$-benzenes). Typical VOC fluxes were in the range $0.1-1.0 \mathrm{mg} \mathrm{m}^{-2} \mathrm{~h}^{-1}$. There was a nonlinear relationship between VOC fluxes and traffic density for most of the measured compounds. Traffic activity was estimated to account for approximately $70 \%$ of the aromatic compound fluxes, whereas non-traffic related sources were found to be more important for methanol and isoprene fluxes. The measured fluxes were comparable to the estimates of the UK national atmospheric emission inventory for the aromatic VOCs and CO. In contrast, fluxes of the oxygenated compounds were about three times larger than inventory estimates. For isoprene and acetonitrile this difference was many times larger. At temperatures over $25^{\circ} \mathrm{C}$ it is estimated that more than half the isoprene observed in central London is of biogenic origin.
\end{abstract}

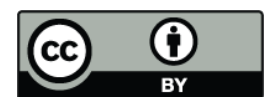

Correspondence to: B. Langford (b.langford1@lancaster.ac.uk)

\section{Introduction}

In urban and suburban settings, emissions from vehicles are the dominant source of most volatile organic compounds (VOCs) to the atmosphere, typically accounting for $>50 \%$ of the total (Kansal, 2009; Na et al., 2005). Direct emissions from vehicle exhaust contribute a large fraction of this total, but other traffic related sources include hot soak emissions during engine cooling (Na et al., 2004; Rubin et al., 2006) and evaporative emissions of petroleum products (Srivastava et al., 2005). Once emitted into the atmosphere, VOCs influence local and regional air quality and can also impact upon human health. Consequently, efforts have been made to curtail and better regulate anthropogenic VOC (AVOC) emissions. In Europe, much of this has been achieved through the implementation of the Geneva VOC and Gothenburg multipollutant protocols (UNECE, 1991, 1999), which promoted the introduction of 3-way catalytic converters to all newly manufactured road vehicles and forced steps to be taken to reduce evaporative emissions from petroleum products.

In order to model the effect of VOC emissions on air quality and to quantify the effectiveness of emission control measures accurately it is necessary to compile spatially disaggregated emission inventories. In the UK (as with many other countries) this is done using a "bottom-up" approach to produce a yearly emission estimate for a large number of air pollutants as part of the UK National Atmospheric Emission Inventory (NAEI) activity.

In contrast to the NAEI, micrometeorological flux measurement techniques such as eddy covariance offer a "top down" approach to quantifying fluxes, giving insight into

Published by Copernicus Publications on behalf of the European Geosciences Union. 
both spatial and temporal changes in VOC emission from a flux "footprint" and their controls, and they offer the opportunity to identify new sources. To date most VOC flux measurements made with these methods have focussed on emissions of biogenic volatile organic compounds (BVOC) from vegetation canopies such as grassland (Karl et al., 2001; Rinne et al., 2001; Warneke et al., 2002; Brunner et al., 2007; Davison et al., 2009) and forests (Karl et al., 2002; Grabmer et al., 2004; Spirig et al., 2005; Lee et al., 2005). However, recent studies have demonstrated that micrometeorological flux measurement techniques can also be extended to the urban canopy, as long as a measurement site with a suitable elevation (at least 3 times the average building height) above street level can be found (Nemitz et al., 2002; Dorsey et al., 2002), and first applications have been made to the measurement of urban VOC fluxes (Velasco et al., 2005, 2009; Langford et al., 2009; Park et al., 2010). To reduce the impact of the surface heterogeneity, variability in the emissions distribution and effects of advection, the eddy covariance measurements are limited to fairly uniform urban areas in terms of topography and patterns of buildings, roads, emission sources and vegetation.

In this study we use disjunct eddy covariance with continuous flow $\left(\mathrm{DEC}_{\mathrm{cf}}\right)$ to measure emission estimates for eight volatile organic compounds above central London. We compare the results to emission estimates within the most recent (2006) NAEI data base for London. We also analyse these data with respect to traffic density and ancillary measurements of $\mathrm{CO}$ fluxes and concentrations.

\section{Experimental}

\subsection{Measurement site}

During the autumn of 2006 (30 September 2006-30 October 2006), micrometeorological measurements of VOC concentrations and fluxes were made over central London. The measurements were conducted as part of the UK CityFlux project, as a contribution to the REgents PArk and Tower Environmental Experiment (REPARTEE-I). The CityFlux project aimed to (i) directly measure pollutant emissions from urban areas, (ii) investigate controls of these emissions, (iii) derive emission factors relative to $\mathrm{CO}_{2}$ and $\mathrm{CO}$ and (iv) study pollutant transformation by comparing fluxes at the plume, street canyon and urban canopy scale.

The site selected to study objectives (i) and (iii) for the UK's largest city was the London Telecom Tower $\left(51^{\circ} 31^{\prime} 17.4^{\prime \prime} \mathrm{N} ;-0^{\circ} 8^{\prime} 20.04^{\prime \prime} \mathrm{W}\right)$, a $188 \mathrm{~m}$ high telecommunications tower, which is located in central London. The tower is surrounded by a mixture of commercial and residential buildings with an average height of $15 \mathrm{~m}$, giving the location an urban classification of 2 (Intensely developed high density urban with 2-5 storey, attached or very closeset buildings) according to the criteria of Oke (2006). The typical daytime flux footprint of the tower is dominated by commercial/residential buildings and roads $(82 \%)$ but also includes urban parkland (13\%) and impervious ground (5\%). A more detailed description of this site has been provided by Harrison et al. (2010).

An ultrasonic anemometer (Model R3-50, Gill Instruments, UK) and gas inlet were attached to a mast which extended $3 \mathrm{~m}$ above the $12 \mathrm{~m}$ tall lattice structure which is erected on the Tower's flat roof. The sample inlet was therefore $\sim 200 \mathrm{~m}$ above ground level. Air was pumped down a $\sim 45 \mathrm{~m}$ long Teflon tube ( $\left.3 / 8^{\prime \prime} \mathrm{OD}\right)$ at a flow rate of $\sim 60 \mathrm{lmin}^{-1}$ to the proton transfer reaction mass spectrometer (PTR-MS) which was housed inside the Tower.

The weather during the campaign was unseasonably warm with an average temperature and relative humidity of $12.2 \pm 1.8^{\circ} \mathrm{C}$ and $84 \pm 8 \%$, respectively. Averaged over England, October 2006 was the third-warmest on record, $2.5^{\circ} \mathrm{C}$ above the long-term mean. South westerly winds dominated during the month of October, with an average wind speed measured at $200 \mathrm{~m}$ of $7.8 \mathrm{~m} \mathrm{~s}^{-1}$. A more detailed overview of the campaign meteorology is given by Harrison et al. (2010) and Nemitz et al. (2010).

\subsection{VOC sampling}

Concentrations of selected VOCs were measured using an Ionicon (GmbH, Innsbruck, Austria) high sensitivity PTRMS which was fitted with three Varian turbo-molecular pumps and a stainless steel ringed drift tube $(9.6 \mathrm{~cm})$. This instrument has been described in detail elsewhere (Lindinger et al., 1998; de Gouw et al., 2007; Hayward et al., 2002); therefore only a description of the instrument setup and operation are included here.

Air for analysis by PTR-MS was purged into the instrument at a flow rate of $0.31 \mathrm{~min}^{-1}$ through a heated Silcosteel ${ }^{\circledR}$ inlet line. The instrument was programmed to operate in two modes, SCAN and FLUX. During the first five minutes of every hour the total mass range $(\mathrm{m} / \mathrm{z}, 21-$ 146) was scanned to provide basic concentration information on a wide range of hydrocarbons. The PTR-MS was then operated in FLUX mode for two 25 min averaging periods per hour, with the quadrupole scanning through 11 predetermined masses (dwell time $0.1 \mathrm{~s}$ per $\mathrm{m} / \mathrm{z}$ ) in measurement cycles lasting just over $1 \mathrm{~s}$ per cycle. The targeted protonated masses and likely contributing compounds were: $\mathrm{m} / \mathrm{z} 33$ (methanol), $\mathrm{m} / \mathrm{z}, 42$ (acetonitrile), $\mathrm{m} / \mathrm{z}, 45$ (acetaldehyde), $\mathrm{m} / \mathrm{z} 59$ (acetone/propanal), $\mathrm{m} / \mathrm{z} 69$ (isoprene/furan/alkenes), $\mathrm{m} / \mathrm{z} 79$ (benzene), $\mathrm{m} / \mathrm{z} 93$ (toluene) and $\mathrm{m} / \mathrm{z} 107\left(\mathrm{C}_{2^{-}}\right.$ benzenes-ethylbenzene/benzaldehyde/xylene isomers). In addition to these masses, both the primary ion count $\mathrm{m} / \mathrm{z} 21$ $\left(\mathrm{H}_{3}^{18} \mathrm{O}^{+}\right)$and its first cluster $m / z 37\left(\mathrm{H}_{3}^{16} \mathrm{O}^{+} \mathrm{H}_{2}^{16} \mathrm{O}^{+}\right)$were recorded. The remaining 5 minutes of each hour were used to measure the instrument background by sampling air which first passed through a platinum catalyst, again in SCAN 
mode. The catalyst was custom built and consisted of a glass tube packed with platinum catalyst powder, heated to $200^{\circ} \mathrm{C}$.

During the study period the PTR-MS operating parameters, drift tube pressure, temperature and voltage were held constant at $2.06 \mathrm{mbar}, 45^{\circ} \mathrm{C}$ and $600 \mathrm{~V}$, respectively, maintaining an $E / N$ ratio of approximately $125 \mathrm{Td}$. The $\mathrm{H}_{3} \mathrm{O}^{+}$ primary ion count ranged between $(4-9) \times 10^{6}$ ion counts per second (cps) with an average of $7 \times 10^{6} \mathrm{cps}$. Ion counts of $\mathrm{m} / \mathrm{z}, 37$ ranged between 0.89 and $9.3 \times 10^{5} \mathrm{cps}$ with a mean of $3.1 \times 10^{5} \mathrm{cps}$, which represented $4 \%$ of the primary ion signal. Typical normalised ion counts ranged between 1 and 210 ncps for the targeted compounds after background subtraction, with instrument sensitivities in the range of 6.4 (acetonitrile) to $8.2 \mathrm{ncps} \mathrm{ppbv}^{-1}$ (benzene).

Gas standards were not available for on-site calibration of the PTR-MS, hence mixing ratios were calculated using the instrument-specific transmission coefficients and reaction rate constants $(k)$ taken from Zhao and Zhang (2004). Despite careful calculation of transmission coefficients, using a range of gas standards under laboratory conditions, mixing ratios may be subject to systematic errors, which, in some instances can be as much as a factor of two (de Gouw and Warneke, 2007). In the current study, where possible, VOC mixing ratios were verified against measurements made by a GC-FID, as discussed in more detail in Sect. 3.1.

Approximately $530 \mathrm{~h}$ of concentration data and $290 \mathrm{~h}$ of flux data were collected over a 25 day period (30 September 2006-13 October 2006; 19 October 200630 Ocrober 2006).

\subsection{Calculation of fluxes}

Fluxes of individual VOCs were measured using a continuous flow disjunct eddy covariance technique $\left(\mathrm{DEC}_{\mathrm{cf}}\right)$. This technique was pioneered by Karl et al. (2002) and has been described in detail by Langford et al. (2009) and Davison et al. (2009). Briefly, a covariance function between vertical wind velocity measurements $(w)$ and VOC mixing ratios $(\chi)$ is used to determine the flux for each selected compound $\left(F_{\chi}\right)$ :

$F_{\chi}(\Delta t)=\frac{1}{N} \sum_{i=1}^{N} w^{\prime}\left(i-\Delta t / \Delta t_{w}\right) \chi^{\prime}$

Here, primes denote the instantaneous fluctuations about the mean vertical wind and VOC concentration (e.g. $\chi^{\prime}=\chi-\bar{\chi}$ ), $\Delta t$ represents the lag time between wind and PTR-MS measurements, $\Delta t_{w}$ is the sampling interval of the vertical wind velocity measurements $(0.05 \mathrm{~s})$ and $N$ gives the number of disjunct samples (1363) from the PTR-MS during each $25 \mathrm{~min}$ averaging period. Standard rotations of the coordinate frame were applied to correct for tilting of the sonic anemometer and $25 \mathrm{~min}$ averaging period were block averaged. No WPL correction for density fluctuations was applied to these data, as this is inversely proportional to the exchange velocity and was deemed small for the compounds studied here, which all showed large fluxes compared with their concentrations.

The lag time, $\Delta t$, was determined using a crosscorrelation (c-c) function between $w^{\prime}$ and $\chi^{\prime}$ within a $25 \mathrm{~s}$ flux averaging period. The maximum correlation typically occurred between 6 and $10 \mathrm{~s}$. This agreed closely with the same c-c function applied to $\mathrm{CO}_{2}$ data recorded by a fast response instrument (Infrared gas analyzer LI-COR 7000) which sub-sampled the same sample air flow directly after the PTR-MS, and the theoretical value of $4 \mathrm{~s}$, calculated from the volume of the inlet line and the flow rate. The precision of each measurement was determined following the criteria specified by Spirig et al. (2005), using the standard deviation of the covariance function at distances far from the peak value to characterise the random noise. Assuming a normal distribution, multiplying the standard deviation by 3 gives the measurement precision at the $99.7 \%$ confidence interval. This value was used as a proxy for the flux limit of detection and only data that exceeded this threshold are presented here. In addition to VOC measurements, fluxes of $\mathrm{CO}$ were measured with a fast-response VUV CO analyser (AeroLaser AL5002) and are described in more detail elsewhere (Famulari et al., 2009; Phillips et al., 2010).

\subsection{Flux losses}

All flux measurement techniques are, to some extent, bandwidth limited and therefore measurement frequency and choice of averaging period become important considerations. During the REPARTEE-I campaign the quadrupole dwell time was set to $0.1 \mathrm{~s}$ per $m / z$, yet the response time of the instrument may be as much as $1 \mathrm{~s}$, resulting in turbulent fluctuations in the $<1 \mathrm{~Hz}$ frequency range being attenuated during the measurement process. Corrections for such flux losses are available (Horst et al., 1997). However at a measurement height of $200 \mathrm{~m}$, the typical eddy size is sufficiently large that fluctuations in this high frequency range carry only a very minor proportion of the total flux (estimated from Horst, $<2 \%$ ). Therefore no correction was applied here. Conversely, measurements made at this elevation may be subject to attenuation at the lower end of the frequency spectrum as the chosen averaging period may not fully resolve low frequency fluctuations without compromising the stationarity of the measurement.

In order to investigate this effect, sensible heat flux data from the campaign were re-analysed by joining individual 25 min files to create averaging periods of 25, 60, 90, 120 and $150 \mathrm{~min}$ (with 5-min gaps). A coordinate rotation was applied to the resulting files which acted as a high pass filter (Finnigan et al., 2003) to the three dimensional wind velocity measurements, ensuring that fluctuations from eddies with a time period greater than that of the averaging period could not contribute to the flux measurement (Moncrieff et al., 2004). The resulting fluxes were then compared back to 

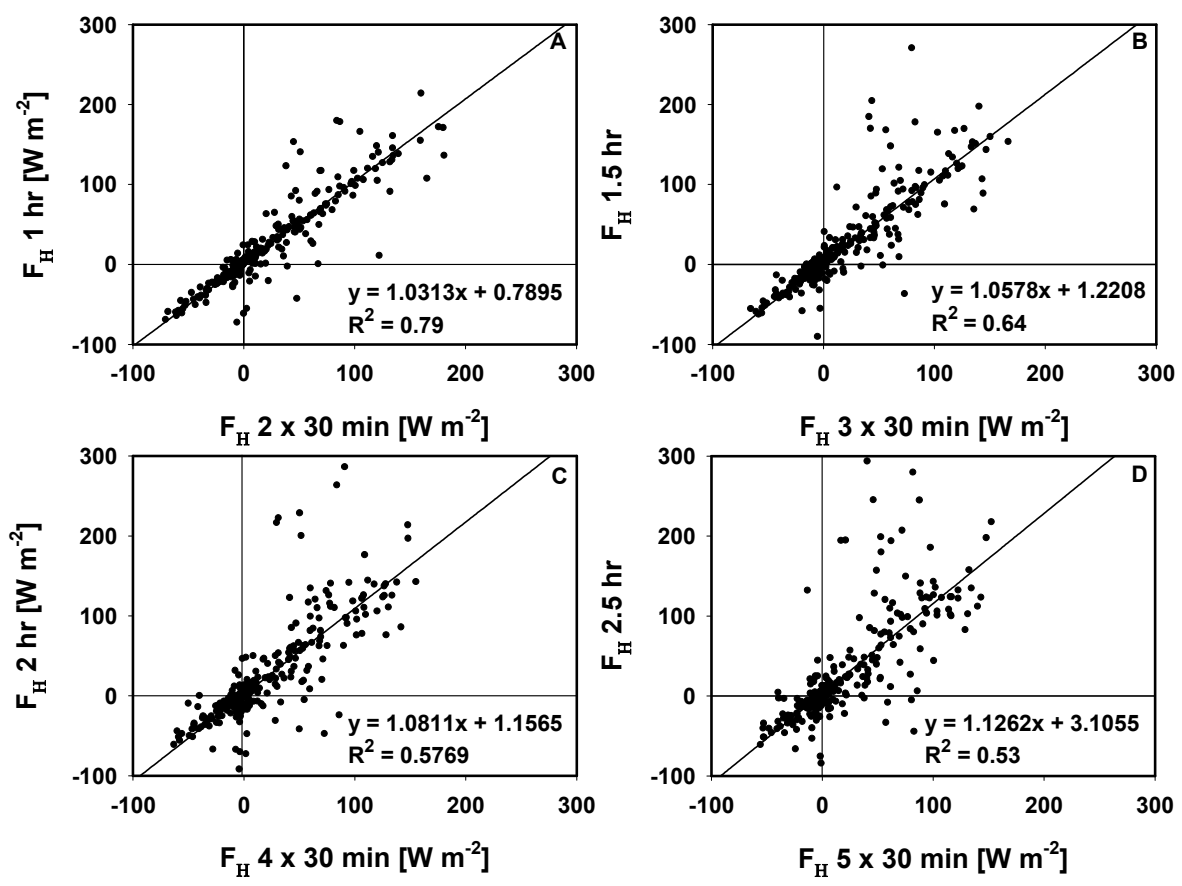

Fig. 1. Fluxes of sensible heat $\left(\mathrm{F}_{H}\right)$ measured at the Telecom Tower calculated using averaging periods of $1,1.5,2$ and $2.5 \mathrm{~h}$ and compared with fluxes calculated using the more standard 25 min averaging period.

the average values measured using the standard 25 min averaging periods, which were also rotated to ensure the flux was only made up by turbulent fluctuations of $25 \mathrm{~min}$ or less.

The results of this are shown in Fig. 1, where the fluxes calculated from the extended averaging period are plotted against the flux constructed by averaging the results from the individual consecutive 25 -min averaging periods. Eddies with a time period of between 25 and 60 min increase the flux by $3.1 \%$; similarly eddies with a period of between 1 and $1.5 \mathrm{~h}$ increase the flux by $2.6 \%$. Extending the averaging period further to $2.5 \mathrm{~h}$ shows a total flux increase of $12.6 \%$, but after this little further increase is observed (not shown). Similar results were observed in heat fluxes measured at Nelson Monument, Edinburgh (E. Nemitz, personal communication, 2008) and in CO fluxes measured above Boulder, Colorado (Nemitz et al., 2008).

These findings show that VOC flux measurements made at the Telecom Tower are bandwidth limited with low frequency contributions attenuated due to the choice of averaging period $(25 \mathrm{~min})$. Consequently, VOC fluxes measured at this site may be underestimating the true flux by some 10 to $15 \%$. However, increasing the averaging period for the PTRMS measurements to $2.5 \mathrm{~h}$ would have increased the likelihood of non-stationarities affecting the flux measurements. In addition, lower time resolution in the flux measurements contains less information to study the processes affecting the fluxes, which was an important objective of this work. Thus a $\sim 30$-min averaging time appears to achieve the right balance.

\subsection{Quality assessment of fluxes}

A post-processing algorithm was written in LabVIEW which not only re-processed fluxes but also filtered out data files which did not meet specific quality criteria. The algorithm involved the following steps: (i) calculation and optimisation of lag times using a c-c function, (ii) calculation of VOC fluxes, (iii) calculation of flux precision, rejecting files where the peak in the c-c function was below three times the measurement precision, (iv) testing of the mean frictional velocity, rejecting data files where $u_{*}<0.15 \mathrm{~m} \mathrm{~s}^{-1}$ and (v) testing of fluxes for stationarity, rejecting failed data files. The stationarity test applied here and associated data quality rating is described in detail by Foken and Wichura et al. (1996) and Velasco et al. (2005).

About $1 \%$ of the data were rejected due to lack of stationarity, $25 \%$ were removed because of insufficient turbulence $\left(u_{*}<0.15 \mathrm{~m} \mathrm{~s}^{-1}\right)$ and a further $18 \%$ were rejected as fluxes were below the limit of detection. Of the $56 \%$ of the data that passed the quality assessment, $91 \%$ were ranked as high quality and 9\% low quality. The bulk of rejected data occurred at night time, potentially biasing nigh time fluxes towards higher values. This effect is discussed in more detail in Sect. 3.4.

As the urban environment presents a non-ideal terrain for micrometeorological flux measurements, an assessment of the integral turbulent statistics of the vertical wind velocity $\left(\sigma_{w} / u_{*}=\right.$ standard deviation of the vertical wind velocity normalised by the friction velocity) was carried out, with 
measured values compared with modelled values, which predict $\sigma_{w} / u_{*}$ for a set of ideal conditions (Foken et al., 2004). Classification of data based on this quality test was outlined by Foken et al. (2004) as part of the FLUXNET programme. According to their criteria over $70 \%$ of the current data were rated category 6 or better (suitable for general use) and less than $3 \%$ of the data set qualified for rejection. A more detailed analysis of the turbulence characteristics from this site is presented elsewhere (Wood et al., 2010).

\subsection{Calculation of the flux footprint}

The typical daytime flux footprint for the site was calculated using a simple parameterisation model (Kljun et al., 2004). Although originally developed for dynamically homogenous terrain, this model has been extended to the urban environment with some success (Langford et al., 2009), hence its application here. Footprints were calculated for stable, neutral and convectively unstable conditions and also for the average conditions encountered during the measurement period. The parameters used in the model included: the standard deviation of vertical wind velocity $\sigma_{w}$; friction velocity $u_{*}$; measurement height $z_{m}$; roughness length $z_{0}\left(1 / 10^{\text {th }}\right.$ the average building height); and boundary layer height $z_{i}$. The predicted flux footprints (radius containing $80 \%$ of the flux) are shown in Table 1 along with the parameters used for each set of atmospheric conditions. This analysis confirms the size of the footprint to vary considerably under differing atmospheric conditions, with larger footprints associated with low values of $\sigma_{w}$. In reality, the range of $\sigma_{w}$ and $u_{*}$ measurements made during REPARTEE-I was small when compared to these scenarios. Consequently, the campaign average flux footprint of $4.7 \mathrm{~km}$ is thought to provide a good approximation of the typical flux footprint during the campaign.

\section{Results and discussion}

\subsection{VOC concentrations}

\subsubsection{Concentrations on the Telecom Tower during REPARTEE-1}

Averaged diurnal concentration plots for each of the eight compounds are shown in Fig. 2 and are summarised in Table 2. During the study period, the largest concentrations of most VOCs were recorded during daytime and the lowest at night, indicating that patterns in emission (peaking at day) had a larger effect on concentrations than boundary layer dynamics. The oxygenated VOCs were the most abundant compounds observed which indicates the importance of the photochemistry taking place above central London. Temporal trends on a weekly time scale were also evident, with VOC concentrations typically $20 \%$ higher during weekdays than at weekends. Furthermore, at weekends, concentrations of some compounds began to increase later in the day, typically
Table 1. Meteorological parameters used in the flux footprint model by Klujn et al. (2004) to generate flux footprints from the Telecom tower under a range of atmospheric stabilities.

\begin{tabular}{lrrrrrr}
\hline $\begin{array}{l}\text { Atmospheric } \\
\text { Stability }\end{array}$ & $\begin{array}{r}\sigma_{w} \\
{\left[\mathrm{~m} \mathrm{~s}^{-1}\right]}\end{array}$ & $\begin{array}{r}u_{*} \\
{\left[\mathrm{~m} \mathrm{~s}^{-1}\right]}\end{array}$ & $\begin{array}{r}z_{i} \\
{[\mathrm{~m}]}\end{array}$ & $\begin{array}{r}z_{m} \\
{[\mathrm{~m}]}\end{array}$ & $\begin{array}{r}z_{0} \\
{[\mathrm{~m}]}\end{array}$ & $\begin{array}{r}\text { Footprint } \\
{[\mathrm{km}]}\end{array}$ \\
\hline Stable & 0.05 & 0.3 & 250 & 200 & 1.5 & 14.3 \\
Neutral & 0.05 & 0.5 & 1000 & 200 & 1.5 & 21.6 \\
Unstable & 2.0 & 0.2 & 2000 & 200 & 1.5 & 0.5 \\
Average campaign & 0.3 & 0.4 & 600 & 200 & 1.5 & 4.7 \\
conditions & & & & & & \\
\hline
\end{tabular}

around 07:00 LT (local time), three or four hours later than was typical Monday to Friday. This is consistent with the temporal pattern in $\mathrm{CO}_{2}$ concentrations at this site (Helfter et al., 2010). Throughout the measurement period, concentrations of the oxygenated compounds were highest, followed by those of the aromatics and isoprene.

On a day to day basis, each analyte typically followed one of two patterns. The first, characterised by the aromatic compounds (benzene, toluene and $\mathrm{C}_{2}$-benzenes), had two day-time peaks, one occurring around 09:00 and the second, slightly larger peak between 18:00 and 21:00. A third, much less well defined peak, occurring at around 14:00 was also evident on certain days, although this tended to be more prominent at weekends. In addition to the aromatics, both acetonitrile and acetaldehyde loosely followed this doublepeak trend, whereas acetone and isoprene did not. Instead, for these compounds, only a single midday maximum was observed, followed by a decline in concentration throughout the mid-to late-afternoon and evening.

Methanol concentrations were highly variable on both daily and weekly timescales and therefore did not follow either trend. During the first week of measurements, methanol mixing ratios increased steadily from $7 \mathrm{ppb}$, to a maximum of $80 \mathrm{ppb}$ on 8 October 2006. A slow decline in concentration was recorded in the subsequent days and, following a short disruption to the measurements between 15-19 October, concentrations returned to the level (7-15 ppb) observed at the start of the campaign. Unlike the other VOCs, strong diurnal trends were not apparent for methanol.

Toluene concentrations also showed longer term variations, with much higher concentrations observed between 1-12 October. During this period the concentration ratio of benzene to toluene $(\mathrm{B} / \mathrm{T})$ was 0.07 , which is much lower than the range typically observed in urban air (Heeb et al., 2000). This ratio increased to 0.16 between 19-30 October 2006 and toluene concentrations followed those of benzene much more closely.

In order to assess possible analytical interferences of PTRMS measurements, additional measurements of VOC concentrations were recorded for validation and comparison purposes at a much lower time resolution using a dual column 

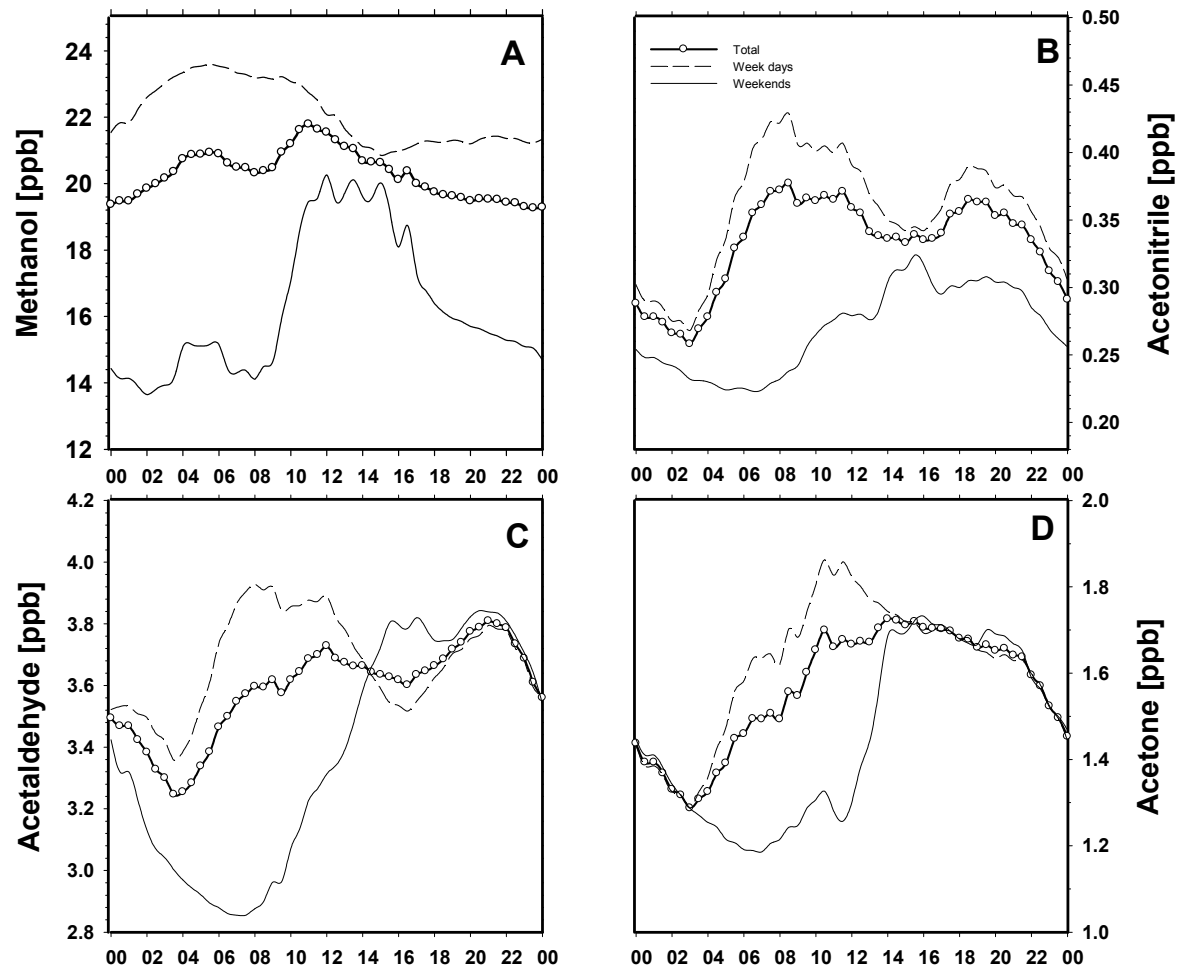

$\begin{array}{llllllllllllll}00 & 02 & 04 & 06 & 08 & 10 & 12 & 14 & 16 & 18 & 20 & 22 & 00\end{array}$
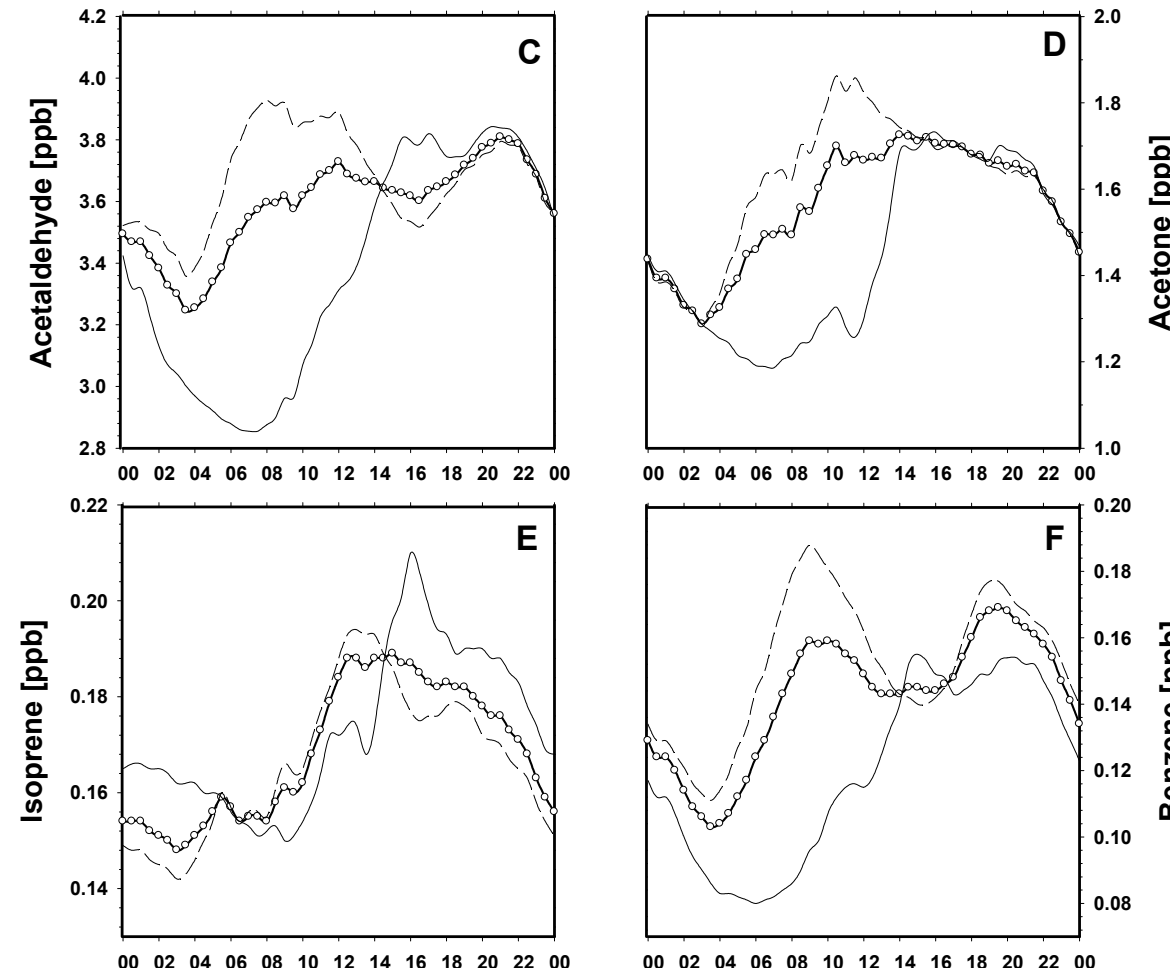

$\begin{array}{lllllllllllll}00 & 02 & 04 & 06 & 08 & 10 & 12 & 14 & 16 & 18 & 20 & 22 & 00\end{array}$
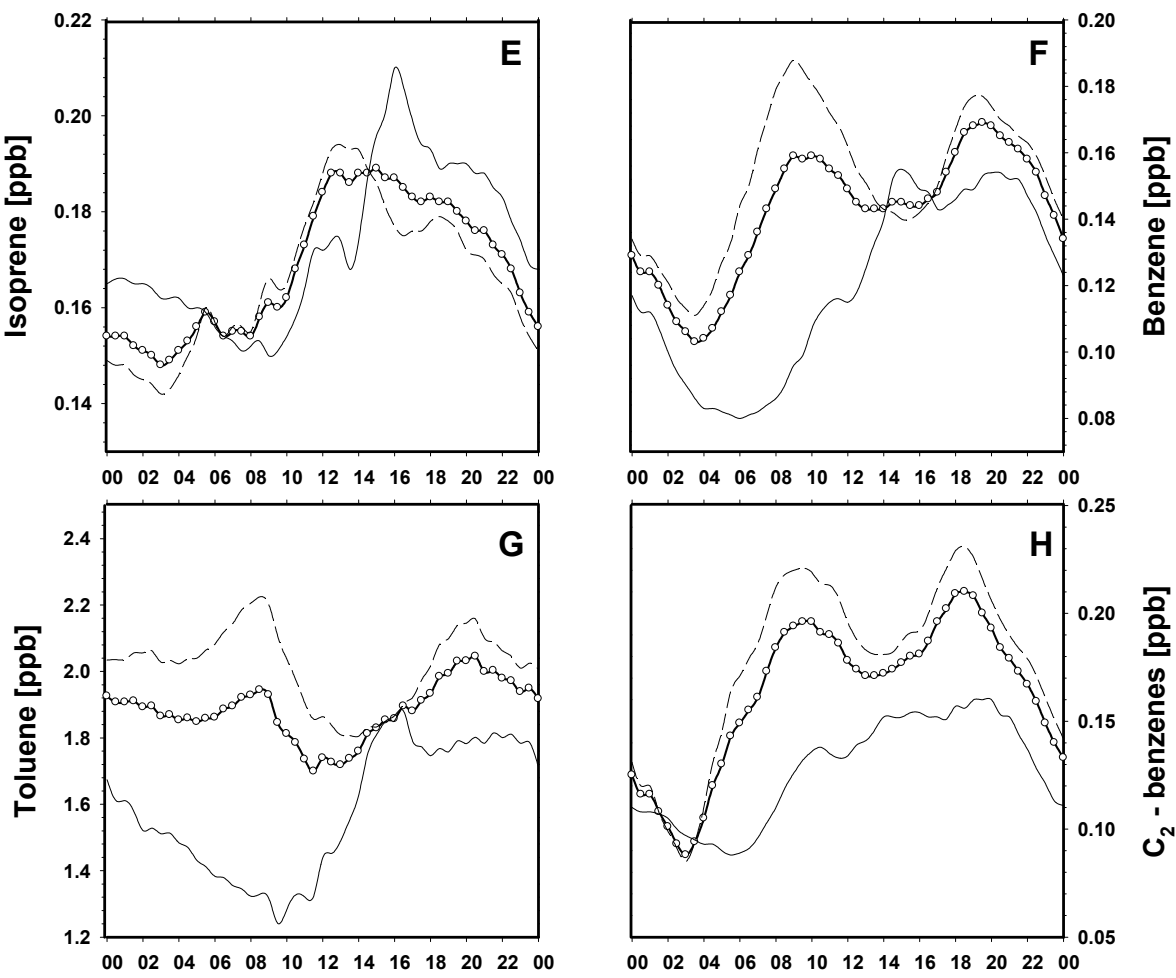

Hour [Local]

$\begin{array}{lllllllllllll}00 & 02 & 04 & 06 & 08 & 10 & 12 & 14 & 16 & 18 & 20 & 22 & 00\end{array}$

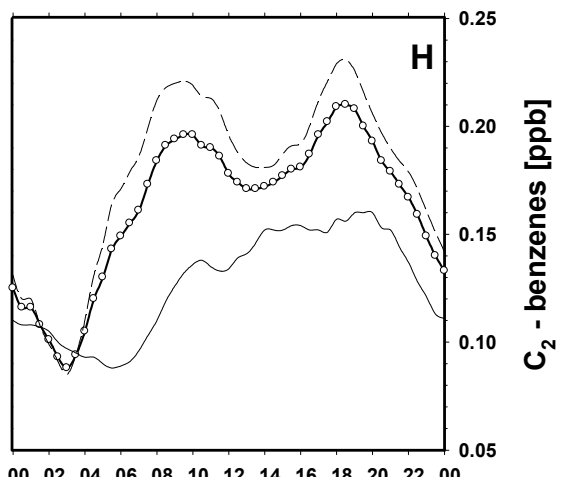

Hour [Local]

Fig. 2. Average diurnal concentrations of volatile organic compounds measured between 30 September and 30 October 2006 . Open circles represent the total average $(25 \mathrm{~min})$ concentrations, solid line represents the average weekend concentrations and the dashed line represents average week-day values. 
Table 2. Summary of VOC concentrations and fluxes measured at the Telecom Tower (London) during October 2006.

\begin{tabular}{|c|c|c|c|c|c|c|c|c|}
\hline & $\begin{array}{r}\text { Methanol } \\
{[\mathrm{m} / \mathrm{z}, 33]}\end{array}$ & $\begin{array}{r}\text { Acetonitrile } \\
{[m / z, 42]}\end{array}$ & $\begin{array}{r}\text { Acetaldehyde } \\
{[\mathrm{m} / \mathrm{z} 45]}\end{array}$ & $\begin{array}{l}\text { Acetone } \\
{[m / z, 59]}\end{array}$ & $\begin{array}{l}\text { Isoprene } \\
{[\mathrm{m} / \mathrm{z} 69]}\end{array}$ & $\begin{array}{l}\text { Benzene } \\
{[m / z, 79]}\end{array}$ & $\begin{array}{l}\text { Toluene } \\
{[\mathrm{m} / \mathrm{z} \text { 93] }}\end{array}$ & $\begin{array}{r}\mathrm{C}_{2} \text {-benzenes } \\
{[\mathrm{m} / \mathrm{z}, 107]}\end{array}$ \\
\hline \multicolumn{9}{|l|}{$\begin{array}{l}\text { Concentrations } \\
\text { [ppbv] }\end{array}$} \\
\hline Mean & 19.4 & 0.33 & 3.57 & 1.57 & 0.17 & 0.14 & 1.85 & 0.16 \\
\hline Median & 12.3 & 0.28 & 3.35 & 1.49 & 0.15 & 0.13 & 1.30 & 0.15 \\
\hline 5-th percentile & 5.4 & 0.19 & 2.48 & 1.00 & 0.08 & 0.06 & 0.47 & 0.06 \\
\hline 95-th percentile & 46.5 & 0.61 & 5.29 & 2.36 & 0.30 & 0.26 & 4.28 & 0.32 \\
\hline $\mathrm{SD}$ & 13.7 & 0.17 & 0.95 & 0.47 & 0.07 & 0.07 & 1.26 & 0.11 \\
\hline $\mathrm{N}$ & 1065 & 1072 & 1065 & 1067 & 1048 & 1067 & 1058 & 1027 \\
\hline \multicolumn{9}{|l|}{$\begin{array}{l}\text { Fluxes } \\
{\left[\mathrm{mg} \mathrm{m}^{-2} \mathrm{~h}^{-1}\right]}\end{array}$} \\
\hline Mean & 0.95 & 0.25 & 0.65 & 0.55 & 0.13 & 0.15 & 0.68 & 0.28 \\
\hline Median & 0.94 & 0.17 & 0.60 & 0.50 & 0.13 & 0.15 & 0.62 & 0.25 \\
\hline 5-th percentile & -0.98 & -0.08 & 0.22 & 0.15 & -0.10 & -0.10 & -0.32 & -0.09 \\
\hline 95-th percentile & 2.2 & 0.82 & 1.33 & 1.24 & 0.26 & 0.29 & 1.57 & 0.63 \\
\hline $\mathrm{SD}$ & 0.93 & 0.27 & 0.38 & 0.40 & 0.10 & 0.11 & 0.57 & 0.21 \\
\hline $\mathrm{N}$ & 512 & 594 & 637 & 641 & 518 & 601 & 589 & 606 \\
\hline
\end{tabular}

SD: Standard deviation;

$\mathrm{N}$ : number of 25-min observations.

gas chromatograph - flame ionisation detector (GC-FID). This system operated between 19-30 October. Glass sample canisters were pressurized with air taken from a balcony approximately $30 \mathrm{~m}$ below the PTR-MS inlet line over $30 \mathrm{~min}$ time periods, with 4-h gaps between samples. Canisters were later analysed offline using a split column GC-FID calibrated with a 74 component hydrocarbon gas standard with individual analytes in the 1-5 ppb range (Apel-Riemer Environmental, Inc.). The results obtained tended to be slightly higher than PTR-MS measurements for compounds in the low $\mathrm{C}_{2}$ $\mathrm{C}_{3}$ range, while the heavier hydrocarbons, shown in Fig. 3, such as benzene, toluene and $\mathrm{C}_{2}$-benzens all showed excellent agreement. This comparison provides independent confirmation that mixing ratios obtained using the specific transmission curve of the PTR-MS were able to yield quantitative results.

Concentrations of benzene, toluene and $\mathrm{C}_{2}$-benzenes (ethylbenzene) were also recorded by the UK Ambient Automatic Hydrocarbon Air Quality Network at their Marylebone road curb site (e.g. Dumitrean, 2008). This site is $900 \mathrm{~m}$ west of the base of the Telecom Tower (Harrison et al., 2010). Comparisons of the trends in concentrations between the two sites were in good agreement for benzene and $\mathrm{C}_{2}$-benzenes with $R^{2}$ values of 0.59 and 0.66 respectively, whereas for toluene, the trend observed at the Tower differed from that seen at street level. Typically, at street level, concentrations of toluene were highest during the day with a broad peak between 08:00 and 18:00 and at their lowest during the night. A comparison of toluene concentrations from the two sites

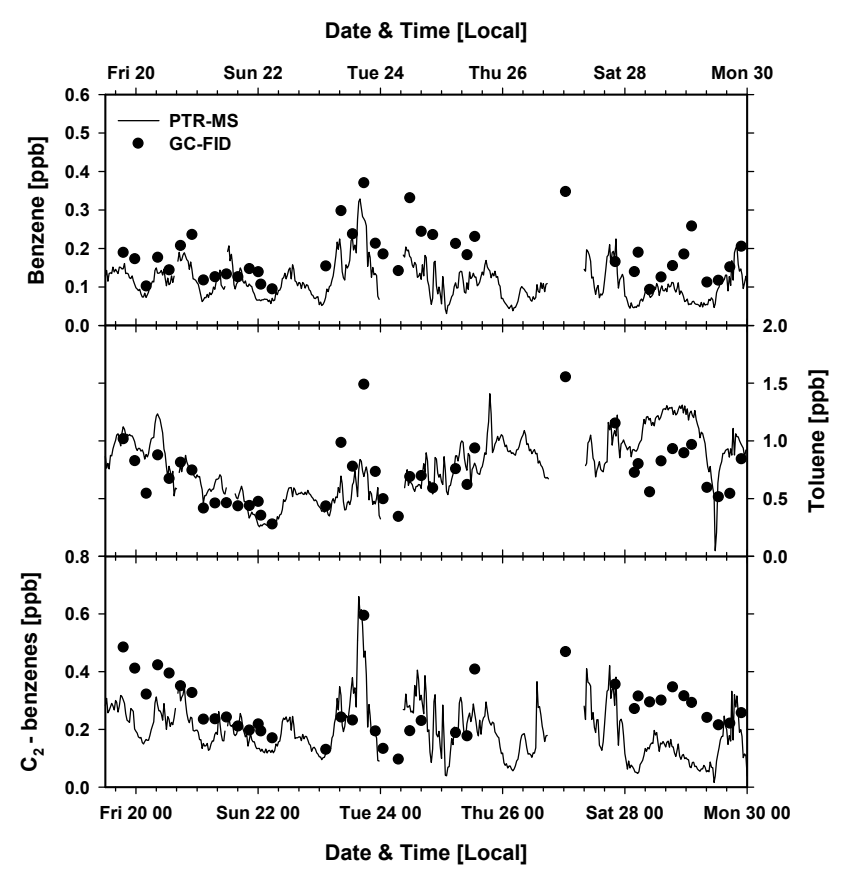

Fig. 3. Mixing ratios of volatile organic compounds obtained by PTR-MS and GC-FID from the Telecom Tower (London) during the REPARTEE-I campaign. 
using data obtained between 19-30 October revealed much closer agreement $\left(R^{2}=0.58\right)$. The higher concentrations observed by the PTR-MS between 1-12 October were not reflected at the Hydrocarbon Network site, which could be suggestive of the PTR-MS detecting additional compounds at $\mathrm{m} / \mathrm{z}$ 93, which would overestimate the toluene measurement. Nevertheless, measurements from the Tower may be strongly influenced by air masses originating from outside of the city, whereas at street level, where the sampling location is in close proximity to the primary emission sources, the influence of advected air masses is likely to be negligible.

Despite the good agreement in concentration trends, curbside measurements were on average twice as high as those observed at the Tower at $200 \mathrm{~m}$ height.

\subsubsection{Meteorology and VOC concentrations at street level in London between 2001-2006}

In order to help place the current results in context, both ambient temperature and VOC concentration measurements were compared against long-term measurements for London for the period of 2001-2006. Temperature data were obtained from the London Weather Centre and showed the annual average temperature for central London to be $12^{\circ} \mathrm{C} \pm 6^{\circ} \mathrm{C}$. The average surface temperature for the month of October over the previous 4 years was $13^{\circ} \mathrm{C} \pm 3^{\circ} \mathrm{C}$. This was very close to the average temperature measured at the Telecom Tower during REPARTEE I $\left(12.2^{\circ} \mathrm{C} \pm 1.8\right)$ and shows the measurement period to be fairly representative of the average annual temperature. However, comparisons with the U.K Met Office long term mean (1971-2000) for south east England showed October 2006 to be unseasonably warm $\left(+2.9^{\circ} \mathrm{C}\right)$.

Long-term measurements of VOC concentrations for the same time period were obtained from the Automatic Urban and Rural Network (AURN) monitoring station located on Marylebone Road. The analysed data included measurements of benzene, toluene and $\mathrm{C}_{2}$-benzenes (ethylbenzene), all of which showed a gradual decrease in concentrations between 2001 and 2006. The average rate of decline during this period was between $-16 \%$ and $-21 \%$ per year, which was in line with the national average during the same time period (Dollard et al., 2007).

Benzene concentrations were typically $18 \%$ higher during the winter (October-April) when compared to the summer (May-September), with the highest concentrations observed in November and the lowest found between April and July. Values recorded in October were $13 \%$ higher than the yearly average, suggesting that measurements in the current study are likely to be slightly larger than the annual average benzene concentration.

Similar winter-summer variation was observed in the measurements of $\mathrm{C}_{2}$-benzenes and toluene, although the difference between the two seasons was less $(9 \%$ and $5 \%$ respectively). Concentration maxima were observed in November and October for toluene and $\mathrm{C}_{2}$-benzenes respectively and were $15 \%$ and $18 \%$ higher respectively than the annual average. Because these concentrations at ground level are not just influenced by the emission strength, but also by mixing processes, which are reduced during the winter months, it is difficult to infer the annual emission pattern from these concentration measurements. Nevertheless, the fact that some concentrations peak in autumn rather than in winter (when mixing is even more suppressed), indicates that our October flux measurements may somewhat over-estimate annual emissions.

\subsection{VOC fluxes}

Figure 4 illustrates the tendency for fluxes to be on average $\sim 19 \%$ lower at weekends than on weekdays. The morning increase in VOC fluxes typically coincided with the increase in traffic which occurred at approximately 07:00. Yet, on some days, VOC fluxes were not seen until much later, between 08:00 and 10:00. During some nights, due to the elevation of the measurement location, the site became de-coupled from the street-canyon activity and both VOC and sensible heat fluxes were only observed as the nocturnal boundary layer broke up in the morning. This phenomenon was most noticeable on the morning of 11 October and is shown here in relation to the typical traffic activity (2006) in Fig. 5. The "saw-tooth" shaped curve is symptomatic of the venting of nocturnal/early morning emissions, initially trapped in the shallow boundary-layer below the measurement height, and can also be seen in the $\mathrm{CO}_{2}$ fluxes (Helfter et al., 2009). Thus, the local flux measured with the DECcf approach at the relatively high measurement height of $200 \mathrm{~m}$ is not always representative for the surface emission at that time. Vertical gradient measurements, required to quantify the storage below the measurement heights, were not available. However, it is expected that the integrated emission over the day nevertheless provides a robust estimate.

Although measurements of boundary layer height (BLH) were not recorded during the REPARTEE-I campaign, estimates of mixed layer depth were made using the algorithm of Arya (1981) and compared with flux data.

$z_{i}=0.142 \frac{u_{*}}{f}$

Here, $u_{*}$ is the friction velocity measured close to ground level at a site near to the Telecom Tower and $f$ is the Coriolis parameter. Although not specifically parameterised for urban meteorology, the model indicates the nocturnal boundary layer to break up between 08:00 and 10:00 and the measurements show the fluxes to rise shortly after. The mixed layer depth estimates show the nocturnal boundary layer below the measurement location $(200 \mathrm{~m})$ at certain times which is consistent with Lidar measurements made during the subsequent REPARTEE-II campaign near to the Telecom Tower. These measurements showed the nocturnal boundary layer to 

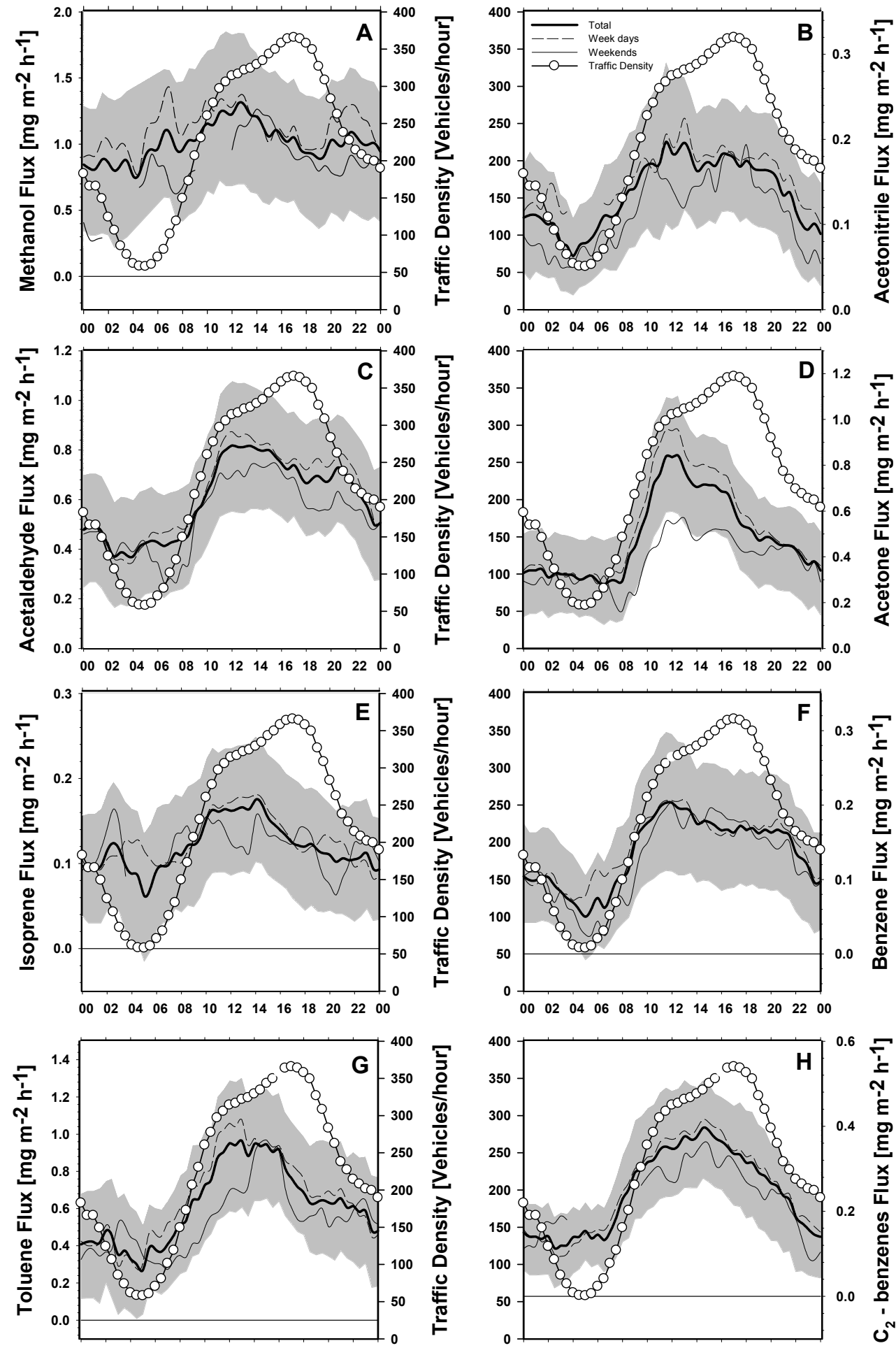

Hour [Local]

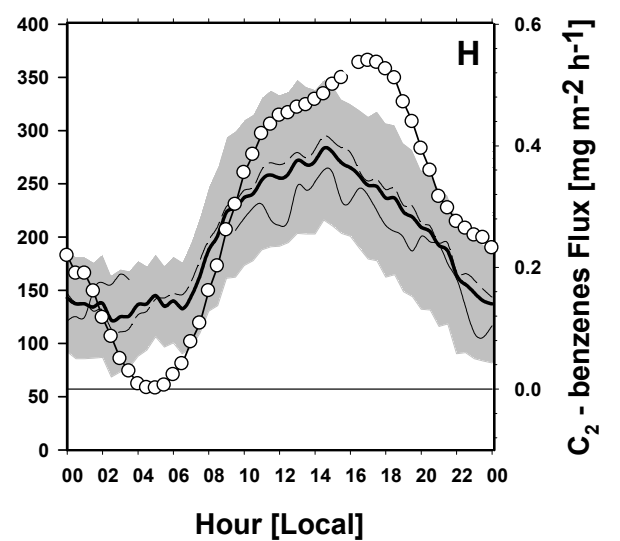

Fig. 4. Average diurnal flux profiles of volatile organic compound fluxes measured during the month of October 2006, from the Telecom Tower, London (UK). Solid bold line represents the total average ( $25 \mathrm{~min}$ ) fluxes, solid line denotes the average weekend fluxes, dashed line represents the average week-day fluxes and open circles show the traffic density. Greyed areas represent the measurement precision - see text. 
Table 3. Average daily VOC fluxes $\left[\mathrm{mg} \mathrm{m}^{-2} \mathrm{~h}^{-1}\right]$ measured over a number of urban areas, including Manchester, UK, and Mexico City. Errors show \pm 1 standard deviation.

\begin{tabular}{|c|c|c|c|c|c|c|c|}
\hline $\begin{array}{l}\text { Location } \\
\text { \& District }\end{array}$ & $\begin{array}{c}\text { Methanol } \\
{[\mathrm{m} / \mathrm{z} 33]}\end{array}$ & $\begin{array}{l}\text { Acetaldehyde } \\
{[\mathrm{m} / \mathrm{z} 45]}\end{array}$ & $\begin{array}{l}\text { Acetone } \\
{[\mathrm{m} / \mathrm{z} 59]}\end{array}$ & $\begin{array}{l}\text { Benzene } \\
{[\mathrm{m} / \mathrm{z} 79]}\end{array}$ & $\begin{array}{l}\text { Toluene } \\
{[\mathrm{m} / \mathrm{z}, 93]}\end{array}$ & $\begin{array}{c}\mathrm{C}_{2} \text { - benzenes } \\
{[\mathrm{m} / \mathrm{z} 107]}\end{array}$ & Source/Comments \\
\hline $\begin{array}{l}\text { London } \\
\text { (Autumn) } \\
\text { [Commercial] }\end{array}$ & $0.95 \pm 0.93$ & $0.65 \pm 0.38$ & $0.55 \pm 0.40$ & $0.15 \pm 0.11$ & $0.68 \pm 0.57$ & $0.28 \pm 0.21$ & This study, $\mathrm{DEC}_{\mathrm{cf}}$ \\
\hline $\begin{array}{l}\text { Manchester } \\
\text { (Summer) } \\
\text { [Commercial] }\end{array}$ & $0.54 \pm 0.71$ & $0.38 \pm 0.68$ & $0.53 \pm 0.66$ & $0.12 \pm 0.18$ & $0.28 \pm 0.41$ & - & Langford et al. (2009), DEC \\
\hline $\begin{array}{l}\text { Mexico City } \\
\text { [Residential] }\end{array}$ & 1.04 & - & 0.4 & - & 0.83 & 0.47 & Velasco et al. (2005), $\mathrm{DEC}_{\mathrm{cf}}$ \\
\hline $\begin{array}{l}\text { Mexico City } \\
\text { [Industrial] }\end{array}$ & - & - & - & $4.7 \pm 2.3$ & $14.1 \pm 4.0$ & - & $\begin{array}{l}\text { Karl et al. (2008), airborne } \\
\text { DEC }_{(\mathrm{cf})} \text {, average midday fluxes }\end{array}$ \\
\hline $\begin{array}{l}\text { Mexico City } \\
\text { [Residential] }\end{array}$ & 1.48 & - & - & 0.40 & 3.06 & 1.33 & Velasco et al. (2009), $\mathrm{DEC}_{\mathrm{cf}}$ \\
\hline
\end{tabular}

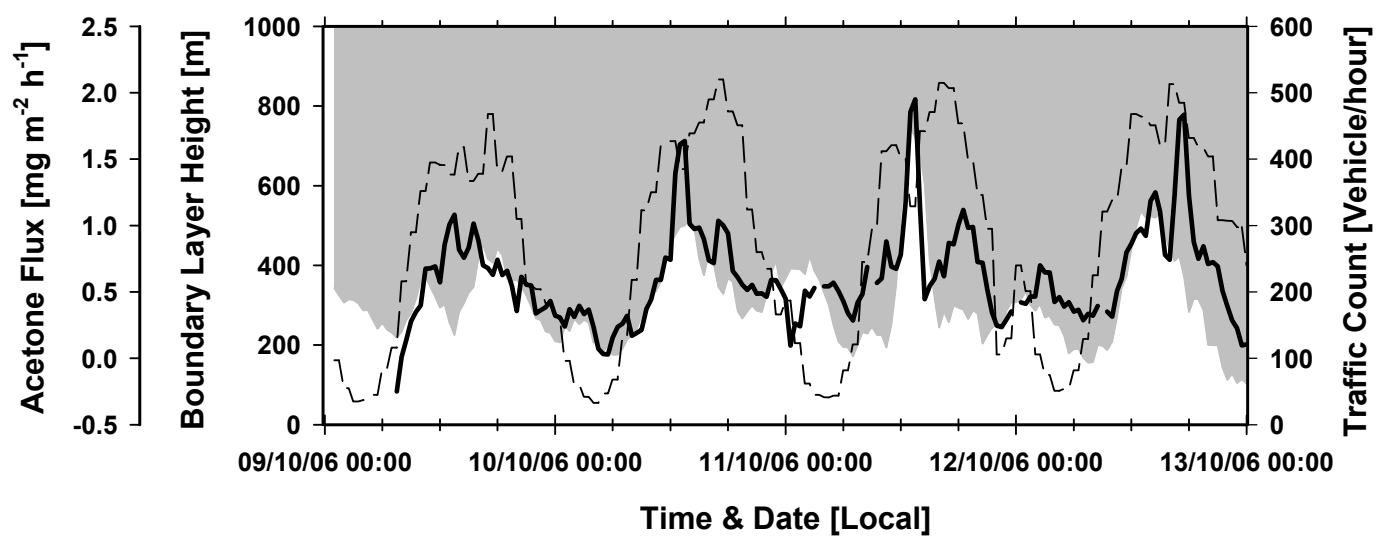

Fig. 5. Graph of acetone fluxes (running mean - solid line) measured during the week of the campaign relative to measured vehicle counts (dashed line) for central London (Marylebone Road). The top of the white layer shows the modelled boundary layer height.

be stratified resulting in a decoupling of the turbulent fluxes at the tower from the street level emissions (Barlow et al., 2010). A comparison between these data and the model during REPARTEE II showed reasonable agreement especially during periods of nocturnal stability, thus giving confidence to the model estimates presented here. It should be noted that an alternative explanation for the higher emissions during the morning compared with the evening rush-hour could be increased emissions associated with cold engine starts.

Throughout the campaign, the largest observed fluxes were of methanol (average daily flux $0.95 \mathrm{mg} \mathrm{m}^{-2} \mathrm{~h}^{-1}$ ), followed by toluene $\left(0.68 \mathrm{mg} \mathrm{m}^{-2} \mathrm{~h}^{-1}\right)$ and acetaldehyde $\left(0.65 \mathrm{mg} \mathrm{m}^{-2} \mathrm{~h}^{-1}\right)$. The magnitudes of the fluxes were variable from day to day, with much larger fluxes observed on certain days: for example, on Wednesday 11 October emission fluxes in excess of $3 \mathrm{mg} \mathrm{m}^{-2} \mathrm{~h}^{-1}$ were recorded for methanol and acetaldehyde. The average daily fluxes are shown in Table 3, which also shows data from VOC flux studies above Mexico City and Manchester.
Fluxes of acetone and methanol were approximately 1.8 times larger in London than the summer time fluxes measured over the city of Manchester. Similarly, fluxes of both benzene and toluene were between 1.3 and 2.5 times larger in London. This is consistent with the observation of larger organic aerosol emission fluxes above London compared with Manchester (Phillips et al., 2010).

Despite the differences in their relative magnitudes, the diurnal flux profiles are roughly similar for each compound and approximately follow the pattern of traffic activity in the city. The absence of a clear two-peak rush hour pattern is consistent with earlier $\mathrm{CO}_{2}$ flux measurements made above the city of Edinburgh (Nemitz et al., 2002). One explanation is that rush hour behaviour tends to be more pronounced on commuter roads, thus affecting concentration measurements which are influenced by air masses advected from outside of the city centre. By contrast, in the central, inner city areas (the flux footprint of the tower), traffic density (and other activities) increases steadily throughout the day. 
Although the fluxes of VOCs followed a similar pattern, there are also differences. For example, acetone emission rates peak in the morning, whereas emission rates of $\mathrm{C}_{2}$ benzenes peak in the afternoon. Some fluxes remain relatively large into the late evening (benzene, toluene and acetaldehyde), while others decrease more rapidly (acetone and isoprene). This may be due to a change in the source mix in the evening (e.g. larger contribution of residential heating sources; shift of the traffic composition away from heavy goods vehicles (as observed in traffic count data); larger fraction of taxi journeys) or a different relative contribution of combustion vs. evaporative sources which respond differently to changes in the meteorological drivers (such as temperature for biological and fugitive sources).

Fluxes of methanol and toluene did not mirror the longer term variations that were observed in measurements of their mixing ratios. This is suggestive of emissions originating from outside the area of the flux footprint being advected over the measurement site, leading to higher concentrations without elevated local fluxes. With an average value of 0.21 , the ratio of benzene to toluene flux is much larger than the $\mathrm{B} / \mathrm{T}$ concentration ratio of 0.08 . Ratios of $\mathrm{B} / \mathrm{T}$ measured from vehicle exhaust are usually in the range of $0.4-0.8$ (Heeb et al., 2000). Therefore, the lower values of the flux ratios observed here suggest emissions from traffic were not the only major source of toluene within the city. Previous urban studies have shown significant emissions of toluene from industrialised areas (Karl et al., 2009) and toluene has numerous anthropogenic sources including solvents, paint thinners and the manufacturing of ink and paints.

\subsection{Wind sector dependence - concentrations and fluxes}

VOC concentration measurements are largely dependent on three factors (i) emission patterns, (ii) meteorology and (iii) chemical processing. In contrast, VOC fluxes are predominantly controlled by emissions only. As a consequence, co-analysis of concentration and flux wind sector dependence can help to identify VOC sources within or beyond the flux footprint. Figure 6 shows normalised VOC concentration and flux wind sector dependence plots in addition to a wind frequency plot for the month of October 2006. As shown, the prevailing wind direction during the campaign was from the south west and therefore statistically significant information cannot be given about VOC sources between $300^{\circ}$ and $60^{\circ}$.

Wind sector dependence plots of VOC concentrations show considerable variation between compounds. For example methanol concentrations were largest towards the SWW, whereas isoprene and ethylbenzene concentrations peaked for easterly wind. In contrast, polar plots of VOC fluxes are roughly similar for each compound and suggest similar source distributions within the flux footprint. The flux polar plots are fairly evenly distributed across each wind sector and therefore emissions from road traffic and other diffuse sources are thought to have been the most likely source of the observed fluxes, rather than individual industrial point sources. Despite the large areas of urban parkland towards the north east (Reagent's Park) and south west (Hyde's Park) of the Telecom Tower no clear association was found for the potentially biogenic compounds isoprene, acetone, acetaldehyde or methanol.

While wind sector dependence plots of concentrations and fluxes agreed for some compounds (acetone, acetaldehyde, $\mathrm{C}_{2}$-benzenes), suggesting both concentrations and fluxes to share a similar source from within the flux footprint, others did not. Wind sector dependence plots of benzene and toluene fluxes for example were very similar, whereas their concentration polar plots showed marked differences. Toluene concentrations were largest towards the south west, while the largest benzene concentrations were associated with south easterly winds. This observation is consistent with the changes in the $B / T$ ratio discussed above and indicates that both toluene and benzene have point sources located outside the footprint of the tower, with different $B / T$ ratio.

\subsection{Ratios of VOC to $\mathrm{CO}$ - concentrations and fluxes}

Measurements of $\mathrm{CO}$ in the urban atmosphere provide a useful marker for anthropogenic combustion emissions. Therefore analysis of the ratios of both concentrations and fluxes of VOCs to $\mathrm{CO}$ can be useful in the determination and identification of sources. Average [VOC]/[CO] concentration (ppbv of $\mathrm{VOC} / \mathrm{ppbv}$ of $\mathrm{CO}$ ) ratios for this campaign and previous urban studies are presented in Table 4 and the typical diurnal pattern of the ratios are shown in Fig. 7 for each compound. Additional information on the $\mathrm{CO}$ mixing ratios and fluxes measured at this site is given by Phillips et al. (2010).

Ratios of benzene and $\mathrm{C}_{2}$-benzenes with $\mathrm{CO}$ concentrations remained relatively constant throughout the daytime, indicating a common source and a similar chemical lifetime. For the remaining compounds, ratios with $\mathrm{CO}$ all followed a similar trend, with a higher ratio during the night-time and mid-afternoon. The two troughs in the $[\mathrm{VOC}] /[\mathrm{CO}]$ ratio coincide with peak traffic flows on the commuter roads outside of the city centre. Explanations for these troughs may include the following: (i) emissions of CO may be elevated in congested traffic situations relative to VOC emissions (Heeb et al., 2000), or (ii) during transport the air is photochemically processed before reaching the tower and therefore the VOCs are depleted in relation to $\mathrm{CO}$, which reacts in the atmosphere more slowly. The most likely explanation, however, is that some of the VOCs have additional sources that are not related to combustion and that make a larger relative contribution outside the rush hour periods.

The average flux ratios of $\mathrm{VOC} / \mathrm{CO}$ (mole $\mathrm{m}^{-2} \mathrm{~h}^{-1} / \mathrm{mole}^{-2} \mathrm{~h}^{-1}$ ) differ from concentration ratios, which is an indication that some of the sources contributing to the concentration measurements were located outside the flux footprint. Between the hours of 08:00 and 

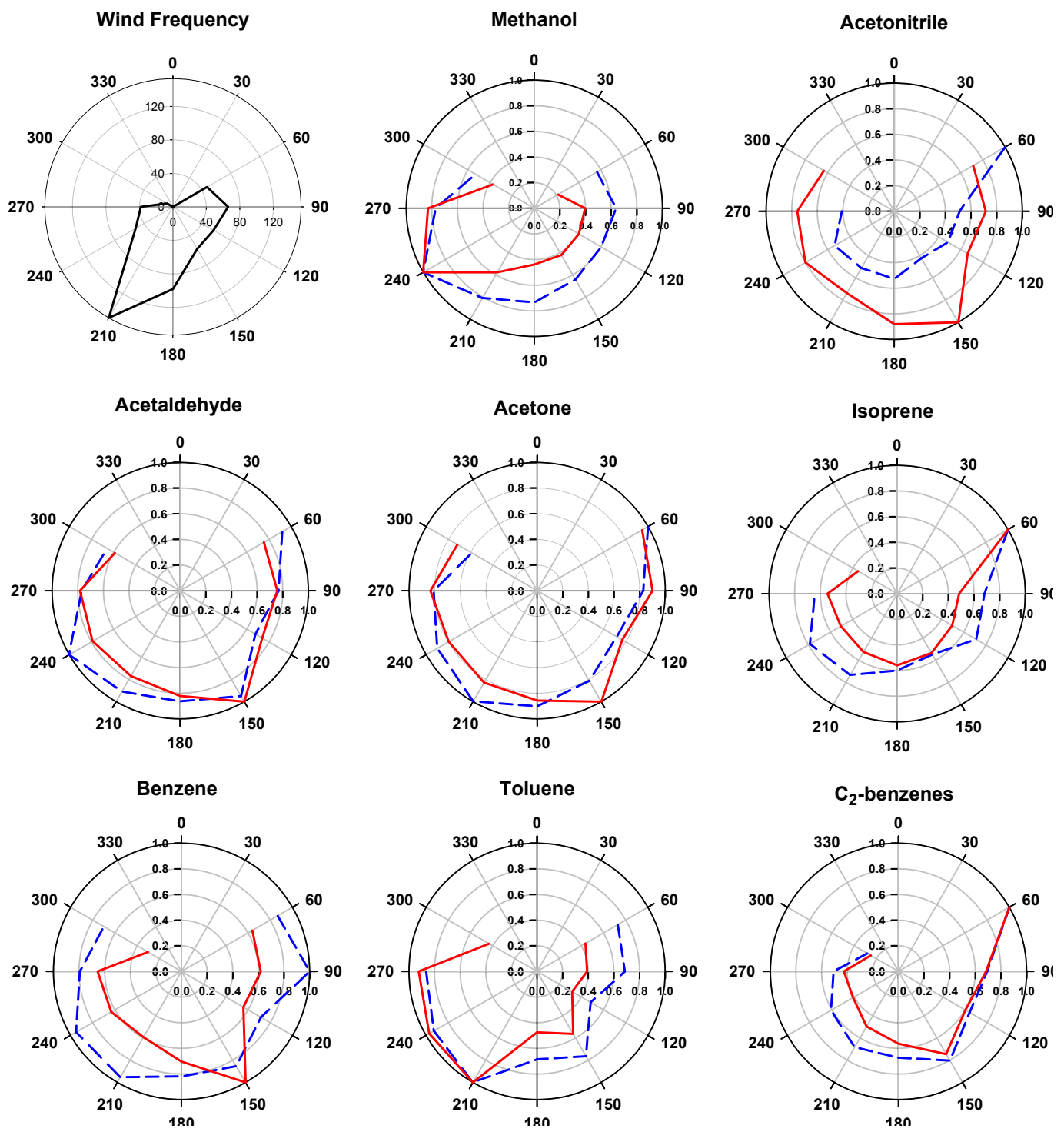

Fig. 6. Normalised polar plots of VOC concentrations (red line) and fluxes (dashed blue line) for the period of October 2006, measured from the Telecom Tower.

23:00 the ratio of $\mathrm{VOC} / \mathrm{CO}$ remains relatively constant, which is suggestive of a common source. However, during the night time (00:00 to 07:00) the ratio becomes elevated, with more VOC flux relative to CO flux, peaking at typically 2 to 3 times the daytime values. This increase is likely to be linked to a shift in the source mix during the night, with heating sources and diesel taxis making a larger relative contribution to the emissions. In addition, the characteristic times for transport and chemical processing change during night and photochemical processing of the VOCs is strongly suppressed, not just due to the absence of sunlight, but also due to the titration of $\mathrm{O}_{3}$ by $\mathrm{NO}$ at street level as reflected in ground level ozone measurements from the Automatic Urban and Rural Network air quality monitoring site located on Marylebone Road. However, it cannot be ruled out that the post-processing of the data also affected the flux ratio. The VOC/CO flux ratio is based on paired measurements when the VOC flux exceeded the calculated limit of detection, which may have resulted in a systematical bias towards higher values.

\subsection{VOC flux dependence on traffic activity}

Traffic density data recorded on Marylebone Road (2006) were used as a proxy for traffic activity across the whole flux footprint and were compared with the measured VOC fluxes (Fig. 8). These plots indicate a clear relationship with traffic, with an increase in both $\mathrm{VOC}$ and $\mathrm{CO}$ emissions with 

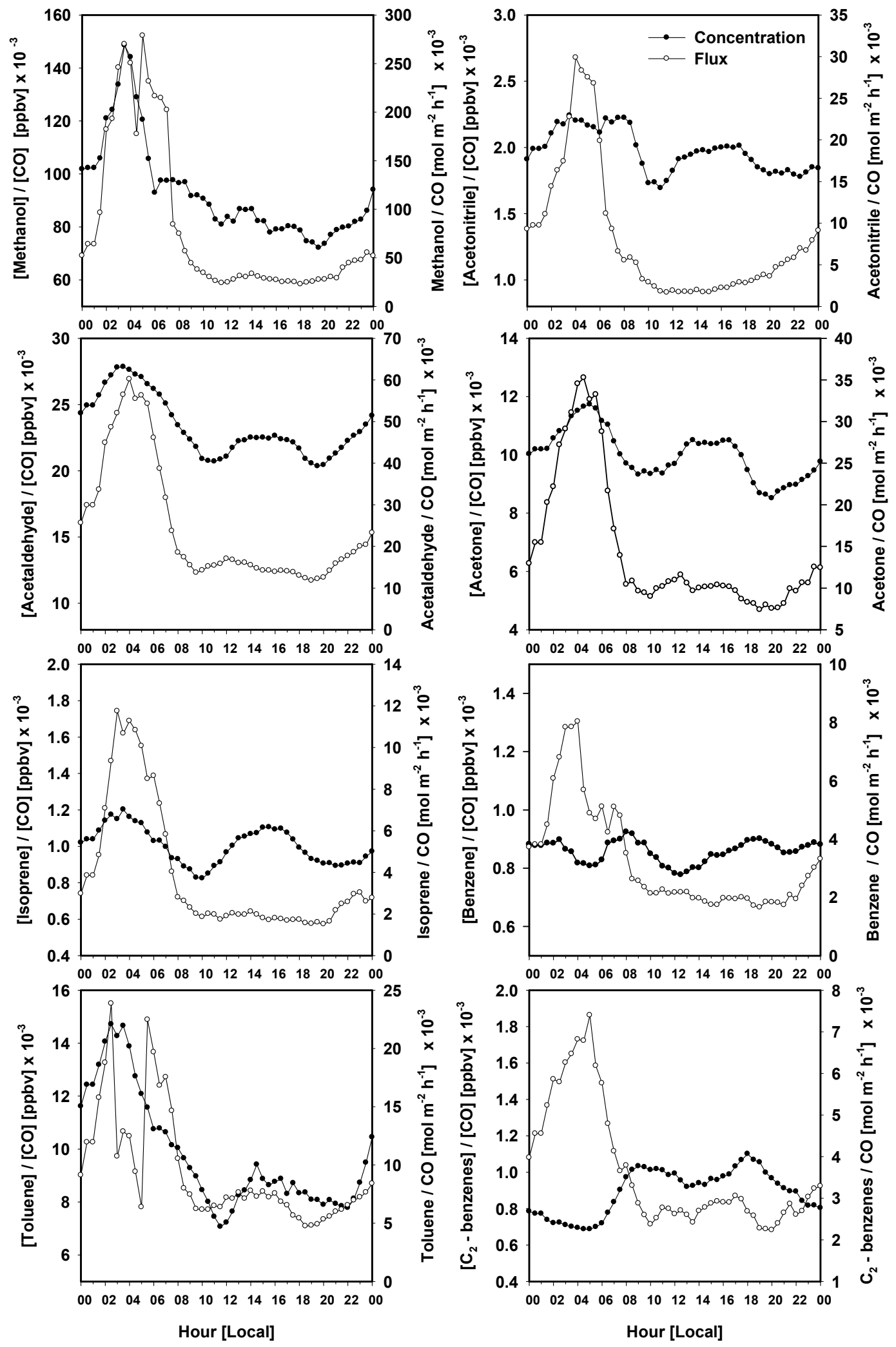

Fig. 7. Ratios of VOC/CO for fluxes (mole $\mathrm{m}^{-2} \mathrm{~h}^{-1} / \mathrm{mole}^{-2} \mathrm{~h}^{-1}$ ) and concentrations ([ppbv]/[ppbv]) (25 min averaged values) for the period of October 2006, measured from the Telecom Tower, London (UK). Closed circles represent concentration ratios and open circles show flux ratios. 
Table 4. Averaged VOC/CO ratios for concentrations and fluxes measured on the London tower.

\begin{tabular}{lcccccc}
\hline \multirow{2}{*}{ Compound } & \multicolumn{2}{c}{ London [ppbv/ppbv] } & \multicolumn{2}{c}{ US - Urban [ppbv/ppbv] } & \multicolumn{2}{c}{ London [mole $\left.\mathrm{m}^{-2} \mathrm{~h}^{-1} / \mathrm{mole}^{-2} \mathrm{~h}^{-1}\right]$} \\
\cline { 2 - 7 } & {$[\mathrm{VOC}] /[\mathrm{CO}]$} & $R^{2 * *}$ & {$[\mathrm{VOC}] /[\mathrm{CO}]$} & $R^{2}$ & VOC/CO & $R^{2 * *}$ \\
\hline Methanol & $9.31 \times 10^{-2}$ & 0.01 & - & - & $8.12 \times 10^{-2}$ & 0.42 \\
Acetonitrile & $1.97 \times 10^{-3}$ & 0.85 & - & - & $7.95 \times 10^{-3}$ & 0.86 \\
Acetaldehyde & $2.33 \times 10^{-2}$ & 0.74 & - & - & $2.44 \times 10^{-2}$ & 0.94 \\
Acetone & $1.00 \times 10^{-2}$ & 0.71 & - & - & $1.45 \times 10^{-2}$ & 0.77 \\
Isoprene & $1.00 \times 10^{-3}$ & 0.43 & - & - & $3.85 \times 10^{-3}$ & 0.64 \\
Benzene & $8.57 \times 10^{-4}$ & 0.85 & $7.0 \times 10^{-4 *}$ & $0.61^{*}$ & $3.22 \times 10^{-3}$ & 0.93 \\
Toluene & $9.79 \times 10^{-3}$ & 0.05 & $2.7 \times 10^{-3} *$ & $0.44^{*}$ & $9.27 \times 10^{-3}$ & 0.90 \\
C $_{2}$-benzenes & $8.93 \times 10^{-4}$ & 0.94 & $4.0 \times 10^{-4 *}$ & $0.30^{*}$ & $3.64 \times 10^{-3}$ & 0.87 \\
\hline
\end{tabular}

* Baker et al. (2008).

** Correlation between average diurnal plots.

increasing volumes of traffic. As the volume of traffic increases, the roads become congested and the average vehicle speed drops from the permissible $50 \mathrm{~km} \mathrm{~h}^{-1}$ (30 mph) on Marylebone road to $34 \mathrm{~km} \mathrm{~h}^{-1}$ at peak times. Emissions of both VOCs and $\mathrm{CO}$ from vehicles increase with decreasing vehicle speed (Heeb et al., 2000; Jensen, 1995), therefore the slower average vehicle speed, combined with increased "stop-start" driving conditions, explains the non-linear rise in emissions.

The plots show good correlations between the measured fluxes and traffic activity, yet in places the fit to the data is close to the limit of uncertainty. This is particularly noticeable at vehicle counts of between 300 and 330 and is best illustrated in the plots of acetone and toluene. Vehicle counts in this range typically occurred between 08:00 and 11:00, which coincided with the breakdown of the nocturnal boundary layer and subsequent venting of night time and early morning VOC emissions. Therefore, in reality, these points may have been affected by the hysteresis between flux and traffic counts and may have had a much closer fit to the curve. Conversely, when vehicle counts are at their peak, between 18:00 and 20:00, VOC fluxes fall below the curve. In this instance the deviation from the curve would be consistent with the formation of the nocturnal boundary layer.

The intercept of the curve with the zero traffic line was used to estimate the proportion of the flux not attributable to road traffic. For most of the VOCs measured, this figure was around $30 \%$ of the peak fluxes, indicating traffic counts to be a very good surrogate for VOC fluxes at this site. Nevertheless, vehicle counts are not the only contributing factor and the average driving speed, driving conditions and ambient air temperature are all likely to influence the relative source strength of VOCs. It should also be noted that non-traffic emissions during the day associated with anthropogenic activities could correlate with traffic and therefore may be masked by the response of the flux to the traffic counts.
For methanol, non-vehicle-related emissions were estimated to account for $65 \%$ of the total observed flux, while for isoprene this contribution was $47 \%$. Identifying the nontraffic related sources of methanol within the city was not possible due to the large number of potential point and diffuse sources which include both biogenic (leaf wounding, microbial degradation of plant material.) and anthropogenic (solvents, adhesives, dyes, paints and varnishes etc.) emissions. For isoprene the task is simplified as there are just three dominant sources of isoprene to the atmosphere in the urban environment: direct emissions from vehicles, evaporative emissions from petroleum products and biogenic emissions from plants. Biogenic emissions of isoprene are both temperature and light dependent (Loreto and Sharkey, 1990) but may also be influenced by plant phenology, relative humidity and external stresses such as pollution or drought (Guenther et al., 2006). An attempt was made to separate the biogenic fraction of isoprene within the city using 5 years of hydrocarbon data collected between 2001 and 2006 by the Hydrocarbon Network monitoring station situated on Marylebone Road (e.g. Dumitrean, 2008). Scatter plots of isoprene against benzene concentrations were made over a range of ambient air temperatures $(-5-0,0$ $5 \ldots 30-35^{\circ} \mathrm{C}$ ) (surface temperature measurements obtained from the London Weather Centre $-3.1 \mathrm{~km}$ east of Marylebone Road). Benzene is used here as a marker of vehicle emissions. The intercept of the regression line was used to indicate the background concentration of isoprene which was not attributable to direct emissions from vehicles, and the temperature-dependent fraction [\%] was calculated using this value as a percentage of the total isoprene present (5-th-95th percentile range).

In order to isolate the biogenic fraction from the evaporative fraction, a similar procedure was applied to concentrations of iso-pentane, a compound that shares the same two major sources as benzene and has a similar volatility to isoprene, but importantly has no biogenic component. The 

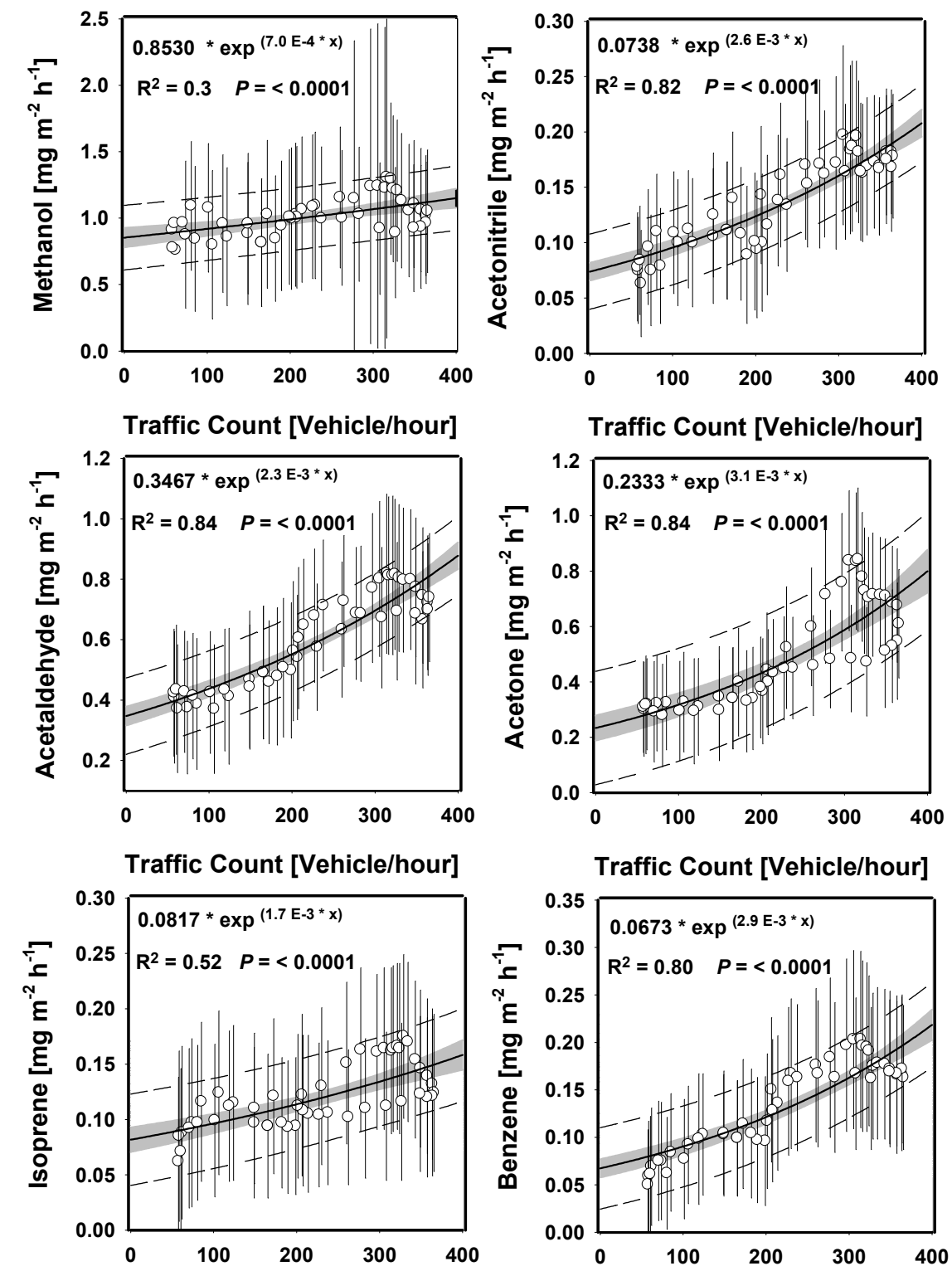

Traffic Count [Vehicle/hour]

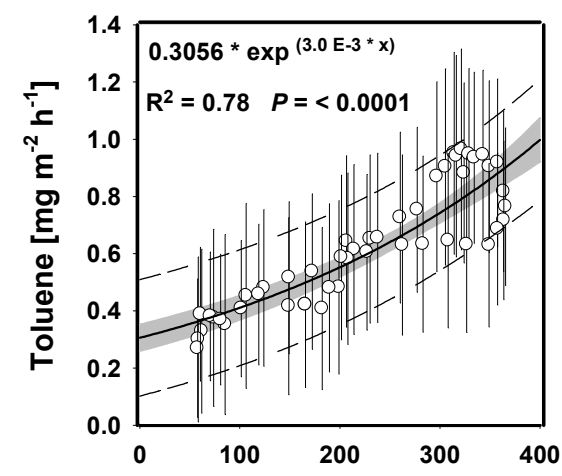

Traffic Count [Vehicle/hour]

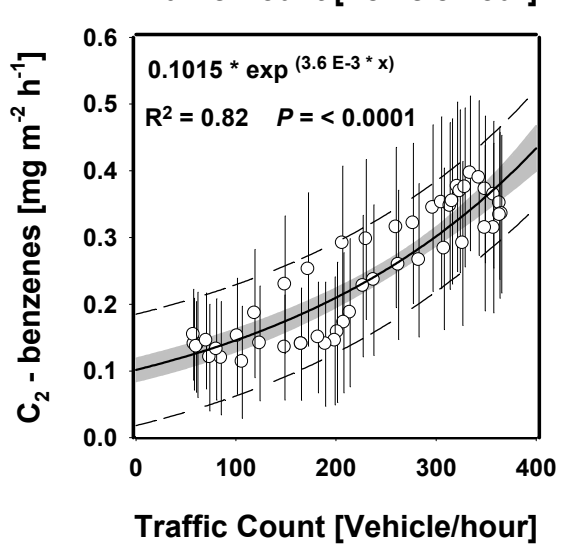

Fig. 8. Scatter plots showing the correlations between VOC flux and measured traffic activity in London city centre (counts - Marylebone Road). Error bars show flux measurement precision, shaded areas show the 95\% confidence bands and dashed lines shoe the $95 \%$ prediction bands. 


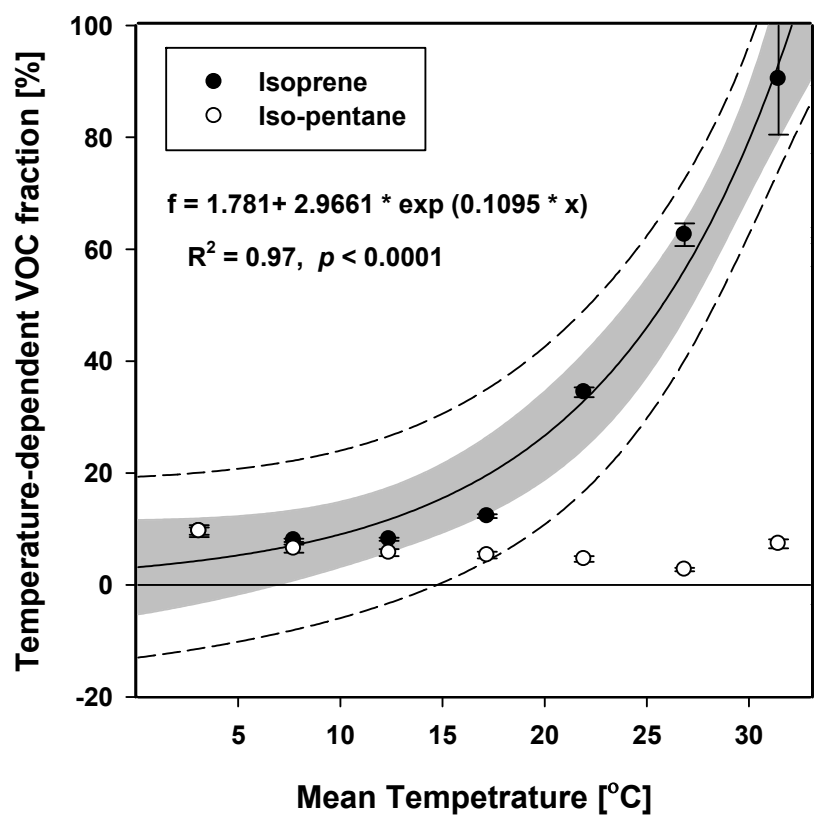

Fig. 9. Temperature dependency of isoprene (closed circles) and iso-pentane (open circles) concentrations, calculated using 5 years of hydrocarbon data collected at the Marylebone Road automatic monitoring station and temperature data from the London weather centre. Error bars show the uncertainty of intercept values for temperature bands $-5-0{ }^{\circ} \mathrm{C}, n=114 ; 0-5^{\circ} \mathrm{C}, n=3405$; 5$10^{\circ} \mathrm{C}, n=9539 ; 10-15^{\circ} \mathrm{C}, n=12176 ; 15-20^{\circ} \mathrm{C}, n=9340 ; 20-25^{\circ} \mathrm{C}$, $n=3171 ; 25-30^{\circ} \mathrm{C}, n=673 ; 30-35^{\circ} \mathrm{C}, n=73$.

results of both analyses are plotted in Fig. 9. Only slight increases in iso-pentane concentrations were found relative to benzene at higher temperatures due to increased evaporative emissions. In contrast, the temperature-dependent fraction of isoprene was large and increased exponentially with temperature. The percentage contribution of biogenic isoprene is thought to be in excess of $\sim 80 \%$ at temperatures of $30^{\circ} \mathrm{C}$. During the REPARTEE-I campaign the average temperature was $12.2^{\circ} \mathrm{C}$ which, using the parameterisation from Fig. 8, equates to a $18 \%$ contribution of temperature controlled (or biogenic) isoprene. This value is not enough to resolve the $47 \%$ non-traffic related sources. Therefore it is likely that other compounds, such as furan and or alkenes are being detected at $m / z 69$, resulting in an overestimation of isoprene concentrations by the PTR-MS.

\subsection{Comparison of measured fluxes with NAEI emission estimates}

The UK National Atmospheric Emission Inventory routinely generates official annual, spatially disaggregated, $1 \times 1 \mathrm{~km}$ gridded emission maps for a wide range of important atmospheric pollutants. A detailed description of the methodology used to generate these maps is given by Bush et al. (2006). Briefly, annual emission estimates are generated

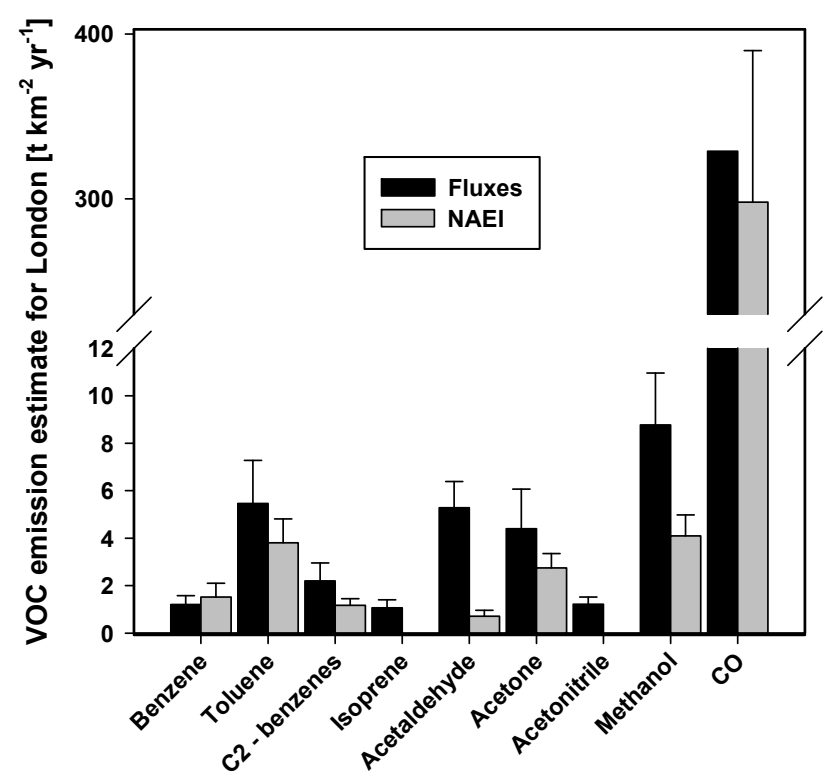

Fig. 10. Flux measurement based emission estimates of VOCs and $\mathrm{CO}$ from the Telecom Tower flux footprint compared with emission estimates made by the NAEI for the same flux footprint area. NAEI estimates for isoprene and acetonitrile are too small to show up on this scale. Error bars show the standard deviation of averaged NAEI grid squares and the $95 \%$ prediction band for the flux parameterisation, where there are no error bars no estimate is given.

from 11 source sectors. Each bottom-up estimate combines reported emissions from point sources with estimates of area sources, the latter calculated theoretically by multiplying emission factors by activity statistics. For example, the emission of benzene from the road transport sector may be expressed as the amount of benzene contained in car exhaust for a driven $\mathrm{km}$ (emission factor), multiplied by the number of kilometres driven within each grid cell per year (activity statistic).

Emission maps are generated for total non methane hydrocarbons (NMHC) each year but speciated emission maps are only provided for benzene and 1-3 butadienes. For those VOCs not explicitly included in this activity, emission maps were generated manually using the total NMHC emission map and the VOC speciation for 2006 (NAEI Reference: 45321001/0/AO6069/NP).

In order to generate an annual emission estimate for each compound that was representative of the area of our flux measurements, the typical flux footprint of the tower was superimposed onto each emission map and the entrained grid squares averaged using a weighting factor to account for the measured wind frequency during the REPARTEE-I campaign. The variability (standard deviation) of grid squares contained within the flux footprint was used as an estimate of the uncertainty in the annual emission estimate and is shown as error bars in Fig. 10. 
VOC flux measurements from October were extrapolated to give an annual emission estimate for comparison with the NAEI. Previously this has been done by simply extrapolating average daily flux measurements to give an annual estimate (Langford et al., 2009). Here, we use the equation of the line from Fig. 8 (Sect. 3.5), where VOC fluxes were plotted against traffic density, to produce an emission estimate using traffic data from Marylebone Road for the whole of 2006. As the parameterisation is based on a "snap-shot" of the total yearly fluxes, this method relies heavily on the assumptions that (i) vehicle emissions account for the bulk of the VOC emissions within the city, (ii) the observed traffic density is representative of traffic activity occurring throughout the flux footprint and (iii) that there is little or no seasonal variation in the emission of VOCs. This last assumption has been shown to be untrue for some of the measured VOC with the contribution from fugitive emissions and cold start engine emissions changing throughout the year, but no correction has been applied here.

The traffic density data set was not continuous over the whole year; therefore, missing sections were filled by repeating data from the equivalent lane of traffic. Where no equivalent data were available, data were taken from the previous year's data set, taking care to match both time of day and day of week. In total less than $20 \%$ of the traffic data set was filled in this way.

Emission estimates for each of the measured VOCs and $\mathrm{CO}$ are shown in Fig. 10 alongside estimates made by the NAEI for the same footprint area. Measured flux estimates are larger than NAEI estimates for all compounds with the exception of benzene which compared very closely. The discrepancy between inventory and flux estimates ranged from a few percent in the case of benzene to several orders of magnitude for both isoprene and acetonitrile. In general, emission estimates of the aromatic compounds, toluene $\left(5.28 \mathrm{t} \mathrm{km}^{-2} \mathrm{yr}^{-1}\right)$, benzene $\left(1.20 \mathrm{t} \mathrm{km}^{-2} \mathrm{yr}^{-1}\right)$ and $\mathrm{C}_{2}$-benzenes $\left(2.2 \mathrm{t} \mathrm{km}^{-2} \mathrm{yr}^{-1}\right)$, compared most closely with the NAEI and on average were 1.4 times greater. Similarly, fluxes of $\mathrm{CO}\left(329 \mathrm{t} \mathrm{km}^{-2} \mathrm{yr}^{-1}\right)$ were very close to NAEI estimates with less than $10 \%$ difference between the two. This is consistent with the close agreement between the NAEI emissions figure for $\mathrm{CO}$ and airborne boundary layer budget measurements (Polson et al., 2010), and the agreement between city-scale CO flux measurements and the NAEI in Edinburgh (Famulari et al., 2009; Phillips et al., 2010).

The difference between flux derived estimates and NAEI was considerably larger for the oxygenated VOCs, acetaldehyde $\left(5.28 \mathrm{t} \mathrm{km}^{-2} \mathrm{yr}^{-1}\right)$, acetone $\left(4.40 \mathrm{t} \mathrm{km}^{-2} \mathrm{yr}^{-1}\right)$ and methanol $\left(8.77 \mathrm{t} \mathrm{km}^{-2} \mathrm{yr}^{-1}\right)$, whose estimates differed by an average factor of 3.3. These findings reflect results from a similar comparison made in Manchester by Langford et al. (2009) as part of the same CityFlux project. Flux estimates of isoprene $\left(1.07 \mathrm{t} \mathrm{km}^{-2} \mathrm{yr}^{-1}\right)$ and acetonitrile $\left(1.22 \mathrm{t} \mathrm{km}^{-2} \mathrm{yr}^{-1}\right)$ were many times larger than those predicted by the NAEI. Emissions from the transport sector are not included in the NAEI for either of these two compounds and emissions from nature are not speciated within the inventory, therefore biogenic emissions, which are likely to contribute a significant fraction of the total isoprene emission, are not included in these NAEI emission estimates. The comparison of October surface concentrations with annual averages (Sect. 3.1.2) suggests that emissions of several compounds may have been larger during this measurement period than at the annual average. By contrast, chemical degradation between emission and arrival at the measurement height was not taken into account explicitly and would lead to an underestimation of the true surface emission, especially for the more reactive compounds (isoprene and acetaldehyde).

\section{Conclusions}

Traffic within the city has been shown to be the primary source of VOC fluxes to the atmosphere within central London, but its relative contribution varies from compound to compound and also temporally, with changes occurring from hour to hour and in the case of isoprene from season to season. It is thought that the relative source strength also varies, with vehicle counts just one of many variables, including air temperature (increased emissions from cold starts vs. increased fugitive emissions), driving conditions (startstop driving in congested areas), vehicle speed (larger emissions at slower average vehicle speeds) and fleet composition (range of fuel/engine types).

The ambient air temperature has also been shown to play an important role in the emission rates of certain VOCs. Isoprene concentrations in the city, for example, are highly dependent on the ambient air temperature, with biogenic emissions, most probably originating from the large areas of urban parkland within the city, thought to contribute as much as $80 \%$ of the total isoprene concentrations recorded at the Marylebone Road monitoring station at temperatures above $30^{\circ} \mathrm{C}$. Such information may be significant in aiding our understanding of VOC precursor emissions associated with photochemical pollution episodes

The close agreement between flux measurements and the NAEI for the aromatic VOCs and CO show the "bottom-up" inventory approach to be effective for air pollutants whose emissions are dominated by one or two sources (e.g. road transport or combustion) which are both well understood and accurately characterised within the inventory. For oxygenated compounds such as acetaldehyde or acetone, emissions can originate from a multitude of point and diffuse sources including paints, solvents and cleaning products which are difficult to characterise within the inventory, and these appear to be grossly underestimated by the official emission inventory. For many other VOCs, including acetonitrile, major sources have yet to be identified and included within the inventory making "top-down" flux measurements essential. 
Acknowledgements. We thank British Telecom for access to the Telecom Tower and the riggers, Bob, Gareth and Zach, who installed the sampling equipment on the lattice tower. The work was funded by the UK Natural Environmental Research Council through the CityFlux grant and an NCAS PhD studentship. The REPARTEE-I campaign was co-funded by the BOC Foundation and co-ordinated by Prof. Roy Harrison and his team at the University of Birmingham. We thank Duncan Whyatt (Lancaster University) for his help with GIS and the emission inventory. We gratefully acknowledge the London Weather Centre for the use of their temperature data.

Edited by: R. M. Harrison

\section{References}

Arya, S. P. S.: Parameterizing the height of the stable atmospheric boundary layer, J. Appl. Meteorol., 20, 1192-1202, 1981.

Baker, A. K., Beyersdorf, A. J., Doezema, L. A., Katzenstein, A., Meinardi, S., Simpson, I. J., Blake, D. R., and Rowland, F. S.: Measurements of non-methane hydrocarbons in 28 United States cities, Atmos. Environ., 42, 170-182, 2008.

Barlow, J. F., Dunbar, T. M., Nemitz, E., Wood, C. R., Gallagher, M., Davies, F., O'Connor, E., and Harrison, R.: Boundary layer dynamics over London, UK as observed using Doppler lidar, Atmos. Chem. Phys. Discuss., in preparation, 2010.

Brunner, A., Ammann, C., Neftel, A., and Spirig, C.: Methanol exchange between grassland and the atmosphere, Biogeosciences, 4, 395-410, 2007, http://www.biogeosciences.net/4/395/2007/.

Bush, T., Tsagatakis, I., King, K., and Passant, N.: NAEI UK Emission, Mapping Methodology, 2006.

Davison, B., Taipale, R., Langford, B., Misztal, P., Fares, S., Matteucci, G., Loreto, F., Cape, J. N., Rinne, J., and Hewitt, C. $\mathrm{N}$.: Concentrations and fluxes of biogenic volatile organic compounds above a Mediterranean macchia ecosystem in western Italy, Biogeosciences, 6, 1655-1670, 2009,

http://www.biogeosciences.net/6/1655/2009/.

de Gouw, J. and Warneke, C.: Measurements of volatile organic compounds in the Earth's atmosphere using proton transfer reaction - mass spectrometry, Mass Spectrom. Rev., 26, 223-257, 2007.

Dollard, G. J., Dumitrean, P., Telling, S., Dixon, J., and Derwent, R. G.: Observed trends in ambient concentrations of C-2-C-8 hydrocarbons in the United Kingdom over the period from 1993 to 2004, Atmos. Environ., 41, 2559-2569, 2007.

Dorsey, J. R., Nemitz, E., Gallagher, M. W., Fowler, D., Williams, P. I., Bower, K. N., and Beswick, K. M.: Direct measurements and parameterisation of aerosol flux, concentration and emission velocity above a city, Atmos. Environ., 36, 791-800, 2002.

Dumitrean, P.: Annual summary of data produced by the UK Ambient Automatic Hydrocarbon Air Quality Network, 2007, http://www.airquality.co.uk/reports/ cat13/0904221401_2007_annual_rep_issue1.pdf, last access: June 2009, AEA Technology plc, Harwell, Report AEAT/ENV/R/2797, UK, 2008.

Famulari, D., Nemitz, E., Di Marco, C., Phillips, G. J., Thomas, R., House, E., and Fowler, D.: Eddy-covariance measurements of nitrous oxide fluxes above a city, Agr. Forest Meteorol., doi:10.1016/j.agrformet.2009.08.003, in press, 2009.
Finnigan, J. J., Clement, R., Malhi, Y., Leuning, R., and Cleugh, H. A.: A re-evaluation of long-term flux measurement techniques part i: Averaging and coordinate rotation, Bound-Lay. Meteorol., 107, 1-48, 2003.

Foken, T. and Wichura, B.: Tools for quality assessment of surfacebased flux measurements, Agr. Forest Meteorol., 78, 83-105, 1996.

Foken, T., Göckede, M., Mauder, M., Mahrt, L., Amiro, B., and Munger, W.: Post-field data quality control, in: Handbook of Micrometeorology: A guide for surface flux measurement and analysis, edited by: Lee, W. M. X. and Law, B., Dordrecht, Kluer Academic Publishers, 29, 181-203, 2004.

Grabmer, W., Graus, M., Lindinger, C., Wisthaler, A., Rappengluck, B., Steinbrecher, R., and Hansel, A.: Disjunct eddy covariance measurements of monoterpene fluxes from a Norway spruce forest using PTR-MS, Int. J. Mass Spectrom., 239, 111115, 2004.

Guenther, A., Karl, T., Harley, P., Wiedinmyer, C., Palmer, P. I., and Geron, C.: Estimates of global terrestrial isoprene emissions using MEGAN (Model of Emissions of Gases and Aerosols from Nature), Atmos. Chem. Phys., 6, 3181-3210, 2006, http://www.atmos-chem-phys.net/6/3181/2006/.

Harrison R. M., Nemitz, E., and Dall'Osto, M., et al.: Atmospheric Chemistry and Physics in the Atmosphere of a Developed Megacity (London): an Overview of the REPARTEE Experiment and its Conclusions, Atmos. Chem. Phys. Discuss, in preparation, 2010.

Hayward, S., Hewitt, C. N., Sartin, J. H., and Owen, S. M.: Performance characteristics and applications of a proton transfer reaction-mass spectrometer for measuring volatile organic compounds in ambient air, Environ. Sci. Technol., 36, 1554-1560, 2002.

Heeb, N. V., Forss, A. M., Bach, C., Reimann, S., Herzog, A., and Jackle, H. W.: A comparison of benzene, toluene and C2 -benzenes mixing ratios in automotive exhaust and in the suburban atmosphere during the introduction of catalytic converter technology to the Swiss car fleet, Atmos. Environ., 34, 31033116, 2000.

Helfter, C., Grimmond, C. S. B., Barlow, J. F., Wood, C. R., Famulari, D., Phillips, G. J., and Nemitz, E.: Long-term measurements of $\mathrm{CO}_{2}$ fluxes above London, Atmos. Chem. Phys. Discuss., in preparation for submission, 2010.

Horst, T. W.: A simple formula for attenuation of eddy fluxes measured with first-order-response scalar sensors, Bound.-Lay. Meteorol., 82, 219-233, 1997.

Jensen, S. S.: Driving patterns and emissions from different types of roads, Sci. Total Environ., 169, 123-128, 1995.

Kansal, A.: Sources and reactivity of NMHCs and VOCs in the atmosphere: A review, J. Hazard. Mater., 166, 17-26, 2009.

Karl, T., Guenther, A., Lindinger, C., Jordan, A., Fall, R., and Lindinger, W.: Eddy covariance measurements of oxygenated volatile organic compound fluxes from crop harvesting using a redesigned proton-transfer-reaction mass spectrometer, J. Geophys. Res.-Atmos., 106, 24157-24167, 2001.

Karl, T. G., Spirig, C., Rinne, J., Stroud, C., Prevost, P., Greenberg, J., Fall, R., and Guenther, A.: Virtual disjunct eddy covariance measurements of organic compound fluxes from a subalpine forest using proton transfer reaction mass spectrometry, Atmos. Chem. Phys., 2, 279-291, 2002, 
http://www.atmos-chem-phys.net/2/279/2002/.

Karl, T., Apel, E., Hodzic, A., Riemer, D. D., Blake, D. R., and Wiedinmyer, C.: Emissions of volatile organic compounds inferred from airborne flux measurements over a megacity, Atmos. Chem. Phys., 9, 271-285, 2009,

http://www.atmos-chem-phys.net/9/271/2009/.

Kljun, N., Calanca, P., Rotachhi, M. W., and Schmid, H. P.: A simple parameterisation for flux footprint predictions, Bound.-Lay. Meteorol., 112, 503-523, 2004.

Langford, B., Davison, B., Nemitz, E., and Hewitt, C. N.: Mixing ratios and eddy covariance flux measurements of volatile organic compounds from an urban canopy (Manchester, UK), Atmos. Chem. Phys., 9, 1971-1987, 2009, http://www.atmos-chem-phys.net/9/1971/2009/.

Lee, A., Schade, G. W., Holzinger, R., and Goldstein, A. H.: A comparison of new measurements of total monoterpene flux with improved measurements of speciated monoterpene flux, Atmos. Chem. Phys., 5, 505-513, 2005, http://www.atmos-chem-phys.net/5/505/2005/.

Lindinger, W., Hansel, A., and Jordan, A.: Proton-transfer-reaction mass spectrometry (PTR-MS): On-line monitoring of volatile organic compounds at pptv levels, Chem. Soc. Rev., 27, 347-354, 1998.

Loreto, F. and Sharkey, T. D.: A gas-exchange study of photosynthesis and isoprene emission in Quercus-rubra 1, Planta, 182, 523-531, 1990.

Moncrieff, J., Finnigan, R. C. J., and Meyers, T.: Averaging, detrending, and filtering of eddy covariance time series, in: Handbook of Micrometeorology: A guide for surface flux measurement and analysis, edited by: Lee, W. M. X. and Law, B., Dordrecht, Kluer Academic Publishers, 29, 7-30, 2004.

Na, K., Kim, Y. P., Moon, I., and Moon, K.-C.: Chemical composition of major VOC emission sources in the Seoul atmosphere, Chemosphere, 55, 585-594, 2004.

Na, K., Moon, K. C., and Kim, Y. P.: Source contribution to aromatic VOC concentration and ozone formation potential in the atmosphere of Seoul, Atmos. Environ., 39, 5517-5524, 2005.

NAEI, National Atmospheric Emission Inventory, 2006.

Nemitz, E., Hargreaves, K. J., McDonald, A. G., Dorsey, J. R., and Fowler, D.: Meteorological measurements of the urban heat budget and $\mathrm{CO}_{2}$ emissions on a city scale, Environ. Sci. Technol., 36, 3139-3146, 2002.

Nemitz, E., Jimenez, J. L., Huffman, J. A., Ulbrich, I. M., Canagaratna, M. R., Worsnop, D. R., and Guenther, A. B.: An eddycovariance system for the measurement of surface/atmosphere exchange fluxes of submicron aerosol chemical species - first application above an urban area, Aerosol Sci. Tech., 42, 636-657, 2008.

Nemitz, E., Phillips, G. J., Di Marco, C. F., Allan, J., Barlow, J. F., Coe, H., Dall'Osto, M., Harrison, R. M., and Williams, P. I.: Controls of concentrations, gradients and fluxes of inorganic reactive gases and aerosol components above London, Atmos. Chem. Phys. Discuss., in preparation for submission, 2010.

Oke, T. R.: Towards better scientific communication in urban climate, Theor. Appl. Climatol., 84, 179-190, 2006.

Park, C., Schade, G., and Boedeker, I.: VOC flux measurements using a novel relaxed eddy accumulation GC-FID system in urban Houston, Texas, Eos Trans. AGU, 89(53), Fall Meet. Suppl., Abstract A41F-0178, 2008.
Phillips, G. J., Thomas, R., Di Marco, C. F. and Nemitz, E.: Fluxes of submicron organic aerosol above three UK urban areas, Atmos. Chem. Phys. Discuss., in preparation for submission, 2010.

Polson, D., Fowler, D., Nemitz, E., Skiba, U., McDonald, A., Famulari, D., Di Marco, C., Simmons, I., Weston, K., Purvis, R., Coe, H., Manning, A., and Webster, H.: Boundary-layerbudget measurements of greenhouse gas emissions at the country scale indicate national inventories underestimate nitrous oxide and methane, Q. J. Roy. Meteorol. Soc., under review, 2010.

Rinne, H. J. I., Guenther, A. B., Warneke, C., de Gouw, J. A., and Luxembourg, S. L.: Disjunct eddy covariance technique for trace gas flux measurements, Geophys. Res. Lett., 28, 3139-3142, 2001.

Rubin, J. I., Kean, A. J., Harley, R. A., Millet, D. B., and Goldstein, A. H.: Temperature dependence of volatile organic compound evaporative emissions from motor vehicles, J. Geophys. Res.-Atmos., 111, D03305, doi:10.1029/2005JD006458, 2006.

Spirig, C., Neftel, A., Ammann, C., Dommen, J., Grabmer, W., Thielmann, A., Schaub, A., Beauchamp, J., Wisthaler, A., and Hansel, A.: Eddy covariance flux measurements of biogenic VOCs during ECHO 2003 using proton transfer reaction mass spectrometry, Atmos. Chem. Phys., 5, 465-481, 2005, http://www.atmos-chem-phys.net/5/465/2005/.

Srivastava, A., Joseph, A. E., More, A., and Patil, S.: Emissions of vocs at urban petrol retail distribution centres in India (Delhi and Mumbai), Environ. Monit. Assess., 109, 227-242, 2005.

UNECE: Protocol to the 1979 Convention on Long-Range Transboundary Air Pollution Concerning the Control of Emissions of Volatile Organic Compounds on their Transboundary Fluxes, United Nations Economic Commission for Europe, Geneva, Switzerland, ECE/EB.AIR/30, 1991.

UNECE: Protocol to the 1979 Convention on Long-range Transboundary Air Pollution to Abate Acidification, Eutrophication and Ground-level Ozone, United Nations Economic Commission for Europe, Geneva, Switzerland, 1999.

Velasco, E., Lamb, B., Pressley, S., Allwine, E., Westberg, H., Jobson, B. T., Alexander, M., Prazeller, P., Molina, L., and Molina, M.: Flux measurements of volatile organic compounds from an urban landscape, Geophys. Res. Lett., 32, L20802, doi:10.1029/2005GL023356, 2005.

Velasco, E., Pressley, S., Grivicke, R., Allwine, E., Coons, T., Foster, W., Jobson, B. T., Westberg, H., Ramos, R., Hernández, F., Molina, L. T., and Lamb, B.: Eddy covariance flux measurements of pollutant gases in urban Mexico City, Atmos. Chem. Phys., 9, 7325-7342, 2009, http://www.atmos-chem-phys.net/9/7325/2009/.

Warneke, C., Luxembourg, S. L., de Gouw, J. A., Rinne, H. J. I., Guenther, A. B., and Fall, R.: Disjunct eddy covariance measurements of oxygenated volatile organic compounds fluxes from an alfalfa field before and after cutting, J. Geophys. Res.-Atmos., 107(D8), 4067, doi:10.1029/2001JD000594, 2002.

Wood, C. R., Lacser, A., Barlow, J. F., Pdhra, A., Belcher, S. E., Nemitz, E., Helfter, C., Famulari, D., and Grimmond, C. S. B.: Flow and turbulence atop a tower of 190 metres above London: a climatology, Atmos. Chem. Phys. Discuss., in preparation for submission, 2010.

Zhao, J. and Zhang, R. Y.: Proton transfer reaction rate constants between hydronium ion $\left(\mathrm{H}_{3} \mathrm{O}^{+}\right)$and volatile organic compounds, Atmos. Environ., 38, 2177-2185, 2004. 